\title{
المدخل النقدي لإعادة بناء الفكر الإسلامي عند العلّامة محمد إقبال
}

$$
\begin{aligned}
& \text { بدران مسعود بن لحسن } \\
& \text { الملخص } \\
& \text { يؤكّد العلّامة محمد إقبال أن صحوتنا الحضارية تنطلق من تقييم ذاتي لمدارس الفكر الإسلامي وتياراته عسبر } \\
& \text { التاريخ لندرك الإخفاقات التي وقع فيها والإبحازات التي حققها، كما يتطلب التمحيص بروح مستقلة لنتائج الفكر }
\end{aligned}
$$

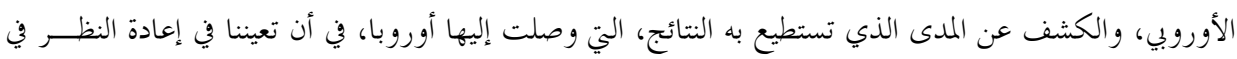

$$
\begin{aligned}
& \text { فكرنا الإسلامي وبنائه من جديد إذا لزم الأمر. } \\
& \text { تدف هذه الورقة إلى تحديد قواعد هذا المدخل النقدي للتراث الفكري الاسلامي وللحضارة الغربيــة الــيت }
\end{aligned}
$$

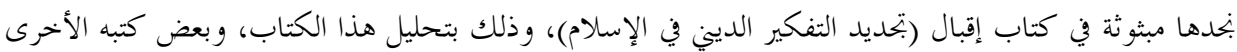

$$
\begin{aligned}
& \text { التي بثّ فيها بعض أصوله النقدية للفكر الإسلامي والفكر الغربي، للوصول إلى تحديد أهم الانتقادات التي انتقد هـا }
\end{aligned}
$$

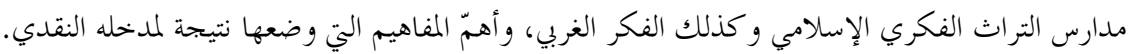

$$
\begin{aligned}
& \text { الكلمات المفتاحية: النقد، التشخيص، التمحيص، الفكر الإسلامي، مادية الغرب، إعادة البناء، روح غربية }
\end{aligned}
$$

\section{Critical Approach to the Renewal of Islamic Thought of Muhammad Iqbal}

\section{Abstract}

Muhammad Iqbal confirms that our cultural awakening should be derived from schools of Islamic thought self-assessment and its development throughout history in order to recognize its failures and achievements. Further, it requires scrutiny in an independent spirit of European thought results and show the extent that these results would help us to re-examine our Islamic thought and to build it again when and where it is necessary.

This paper aims to identify the foundations of this critical approach of Islamic intellectual heritage and west civilization that we find in Iqbal book: "Reconstruction of Islamic Religious Thought". The paper will analyze this book, as well as some of his other writings which have elements of his criticism of Islamic and Western thought to identify Iqbal most important principles of his approach of criticism.

Key Words: Criticism, Diagnosis, Islamic thought, West materialism, Reconstruction, Western spirit.

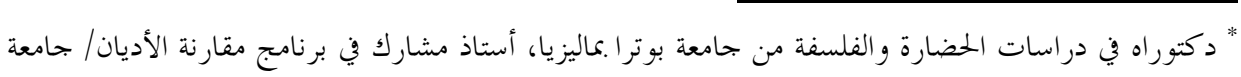

$$
\begin{aligned}
& \text { حمد بن خليفة، البريد الإلكترو ني: gmail.com }
\end{aligned}
$$

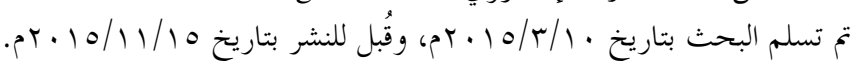


مقدمة:

يسعى الفكر الحضاري الإسلامي إلى إبحاز تنظيري للأطرو حة الحضــارية الــتي

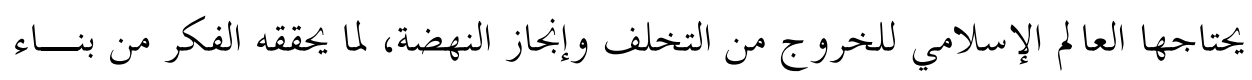
للرؤية والمنهج و المفاهيم اللازمة لعملية التحضّر.

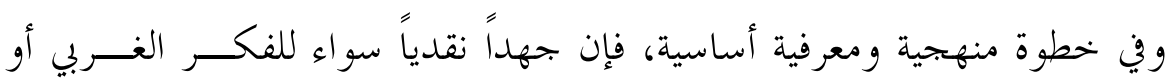

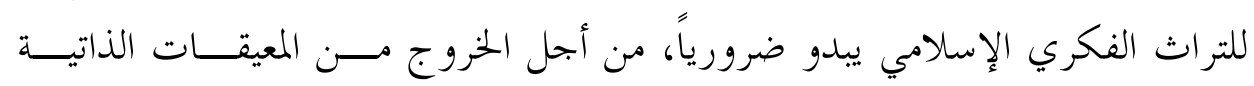
و الموضوعية للفكر الإسلامي.

و في هذا السياق يؤكد العلّامة محمد إقبال -عليه رحمة الله- أن صحوتنا الحضارية تنطلق من تقويم ذاتي لمدارس الفكر الإسلامي وتياراته عبر التاريخ؛ لندرك الإخفاقات التي وقع فيها والإبنحازات التي حققها، كما يتطلب التمحيص بروح مســتقلة لنتــائج الفكر الأوروبي، و الكشف عن المدى الذي تستطيع به النتائج التي وصلت إليها أوروبا أن تعيننا في إعادة النظر في فكرنا الإسلامي وعلى بنائه من جديد إذا لزم الأمر.

لذلك فإن محمد إقبال في كتابه (بحديد التفكير الـــديني في الإســالام) وفي بقيـــة دواوين شعره وأعماله الفكرية، يقدم -من بين ما قدمه من أفكار ومعالجات- مقاربة

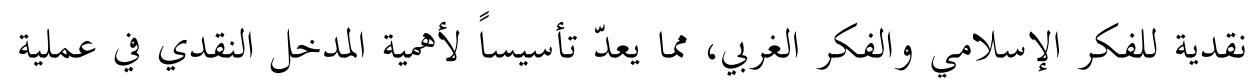
تجديد الفكر الإسالامي.

هدف هذه الورقة للوصول إلى استخراج قواعد هذا المدخل النقـــدي للتـــراث الفكري الإسلامي وللحضارة الغربية التي بجدها مبثوثة في كتاب إقبال (بحديد التفكير الديني في الإسالم) و في بقية دواوين شعره وأعماله الفكرية، وذلك بتحليل هذا الكتاب المكاب

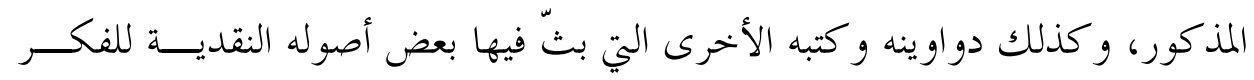

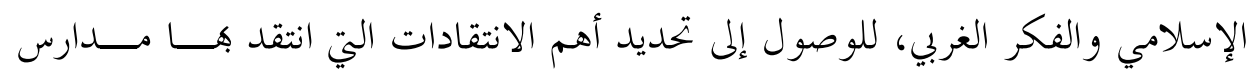

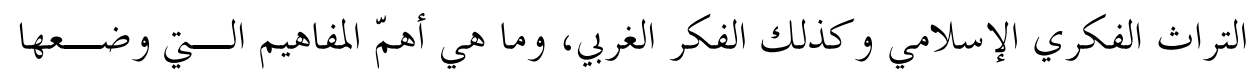
نتيجة لمدخله النقدي. 
ومن أجل تناول منهجي لهذا الموضوع فإين قسمته إلى محاور ثلاثة؛ أولها التعريف بشخصية إقبال في سياق الموضوع الذي يتم تناوله، وثانيها تشخيص إقبال لواقع الأمة،

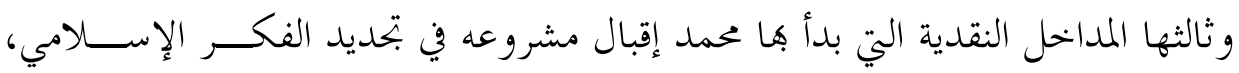

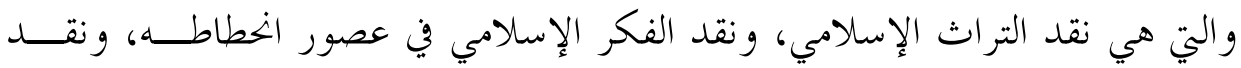
الفكر و الحضارة الغربية.

ذلك أن إقبال يرى أننا كي ننجز تجديداً في الأمة -فكراً وحضارة- ينبغي أن نقوم بخطو تين منهجيتين مهمتين جدا، هما: تشخيص الحالة، والقيام بعملية تمحيص (نقـــد) الموروث، وتمحيص (نقد) الفكر الإسلامي في عصور ركـــده، وتمحهـيص (نقـــــ الحضارة الغربية.

\section{أولاً: شخصية إقبال وفلسفته}

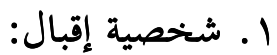

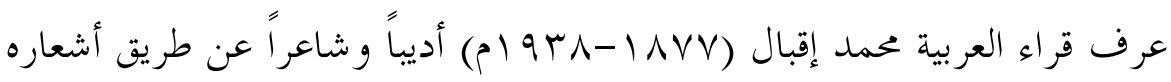

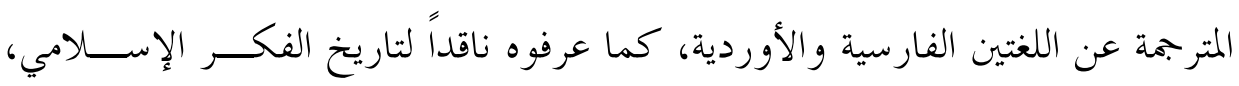
وزعيماً من زعماء الإصلاح في العالم الاسلامي المعاصر.'

و يعدّ إقبال أحد المفكرين القلائل في المحال الفكري الإسلامي الحـــــيث الـــــين

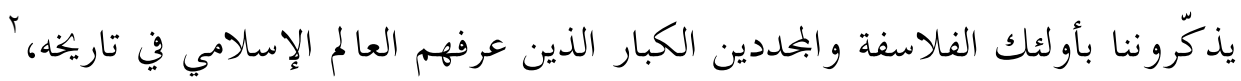
أمثال ابن تيمية و الغزالي وابن رشد وابن خلدون بات وغيرهم.

'إقبال، محمد. تطور الفكر الفلسفي في إيران، ترجمة: حسين الشافعي ومحمد السعيد جمال الدين، الدار الفنيــة

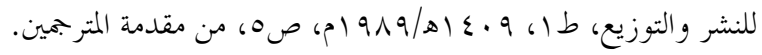

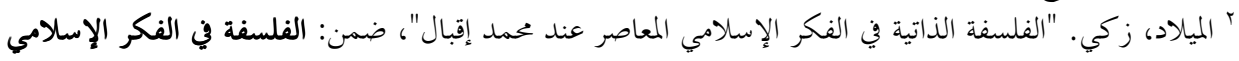

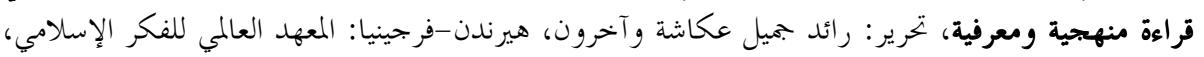




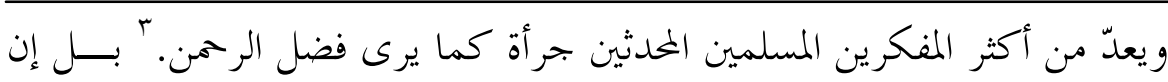
بصيرته تتجلى في دعوته الصريحة للمسلمين في إعادة النظر و الــتفكير في مفهــــمهم

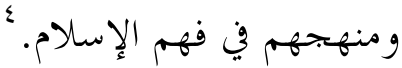

وقد شبّهه الدكتور عثمان أمين بأنه قام .عا قام به كانط في الفكر الغربي. ويــــى ماجد فخري أن التنسيق الذي عمل إقبال على بسطه في كتاب (بحديد التفكير الديني في الإسالام) يشبه في ضخامته التنسيق الذي قام به الغزالي قبل ذلك التاريخ بنحو ألف إن إن

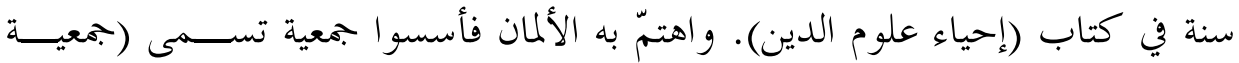
إقبال) هتم بنشر أفكاره و التعريف به، و نصبوا له تمثالاً بساحة جامعة ميونيخ اليت درس بها و حصل على الدكتور اه عام م • 9 (م، وعدّته الباحثة الرو سية (مارييتا ستيبانيانتس) رومي العصر.

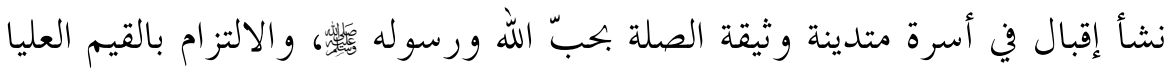
للقر آن الكريّم و سيرة البي عليه الصالاة و السالام. و ونذكر حادثتين من حياته تدلنا على عمق هذا الارتباط بالله و برسوله.

يككي إقبال عن ذلك فيقول: "تعوَّدتُ أن أقراًَ القر آنَ بعد صلاة الصبح كلَّ يوم،

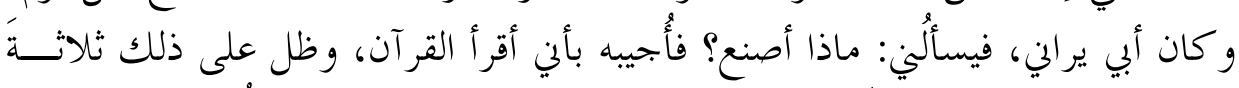

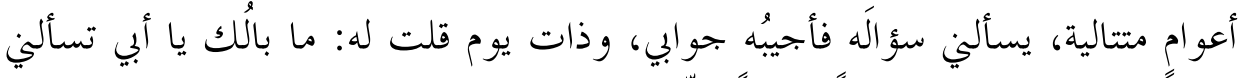

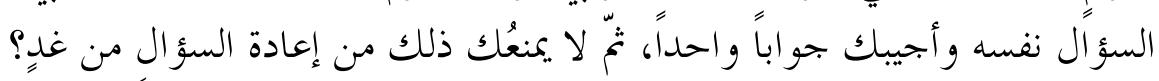

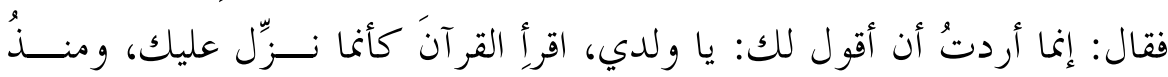
ذلك اليوم بدأتُ أتفهَّم القر آن، و أقبل عليه، فكان من أنواره ما اقتبست، و ومـــن دُرَره

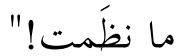
هذه القصة المختصرة قد تعطي صورةً عن حياة إقبال اللاحقة، باعتبار أن طفولته كان تكتسي هذا الطابع، وتأثرت كثيراً بتربية و الده الصوفية، ويدل على عسى حسن تربية و الده له، و تنشئتِه على مأدبة القر آنِ الكريك.

3 Muzaffar, Chandra. "Iqbal and the Challenge of Reform within the Muslim World", Intellectual Discourse, 2000, Vol 10, No 2, p 139.

${ }^{4}$ Ibid.

• الميلاد، الفلسفة الذاتية في الفكر الإسلامي المعاصر عند محمد إقبال، مرجع سابق، صوهץ- . بr. 
و يخبرنا إقبال في ديوانه (رموز بي خودي) عن حادثة أخرى تعبّر عن عمق تــدين

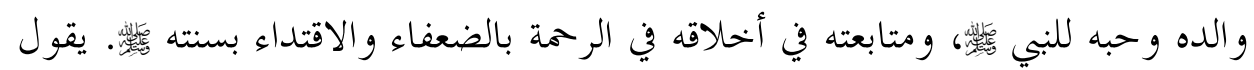

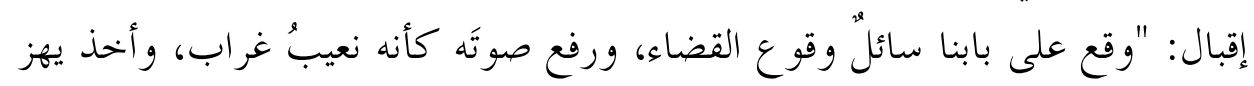

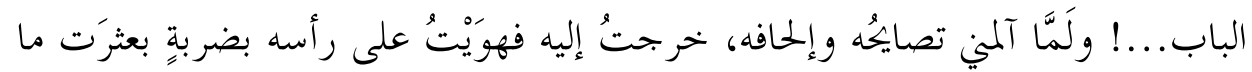

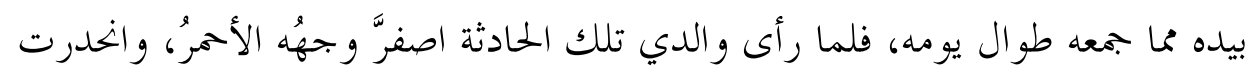

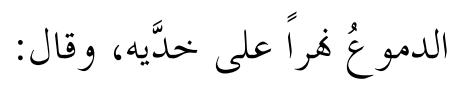
تذكر يا بين جلالَ المحشرَ!

يوم بتحتمع أمةٌ خير البشر، وارجع البصرَ كرة إلى لحيتي البيضاء!

$$
\text { ونحولِ جسمي المرتَعش بين الخوف والرجاء! }
$$$$
\text { كن يا بنيّ من البراعم في غصن (محمَّدِ)! }
$$$$
\text { وكن زهرةً يُحييها نسيمُ ربيع (المصطفى)!" }
$$

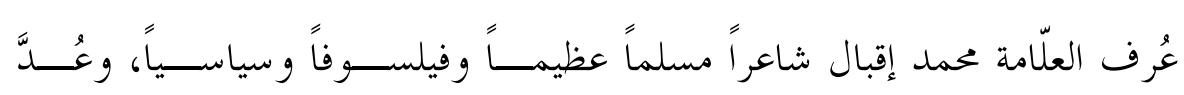

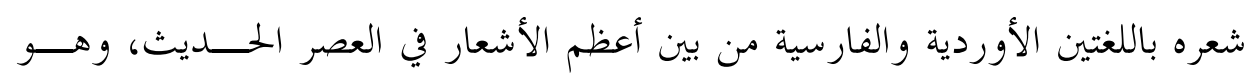

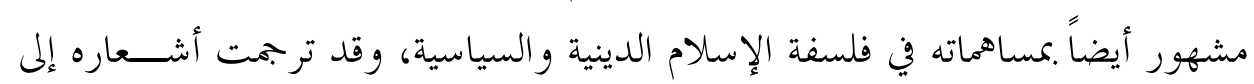
اللغات الإسبانية والصينية و اليابانية والإنجليزية وغيرها.

طغى الشعر على حياة إقبال وو جدانه رغم عشرات المؤلفات في عــــة حقـــول،

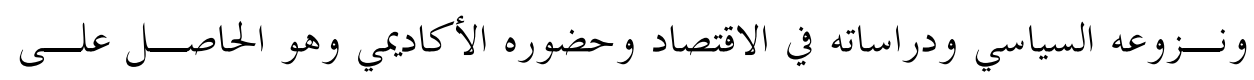
درجة الدكتوراه في الفلسفة من جامعة ميونيخ الألمانية، واشتغاله في المحاماة التي أحبها.

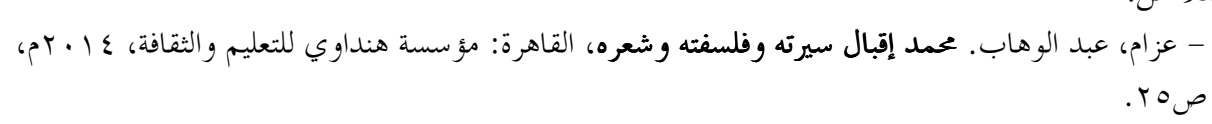

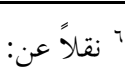

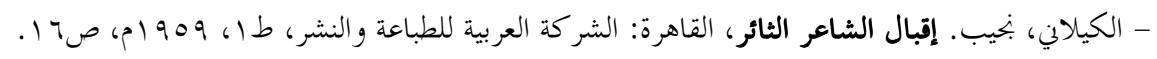

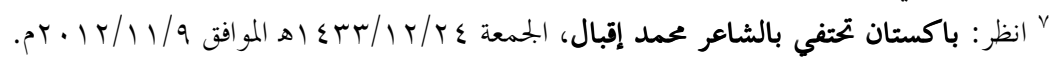
- http://www.aljazeera.net/home/print/f6451603-4dff-4ca1-9c10-

122741d17432/8d630798-c9d4-4c09-a296-49da0561d9d 


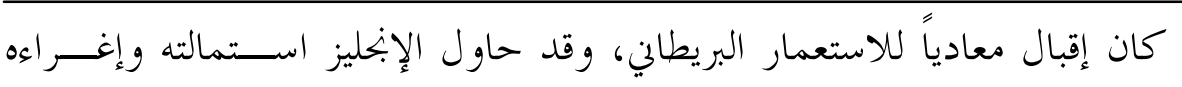

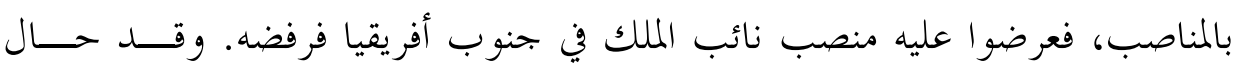

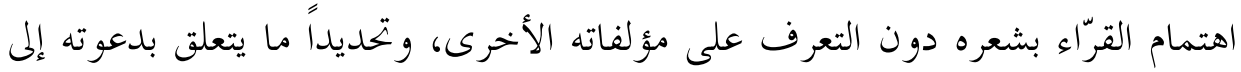

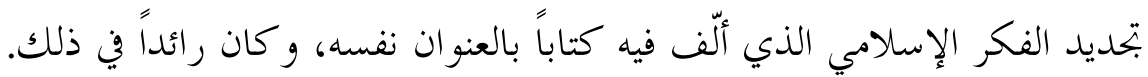
وحمل شعره نفَسَاً فلسفياً صوفياً، ووتثت قصائده لزيار اته وسفراته و انطباعاته عن

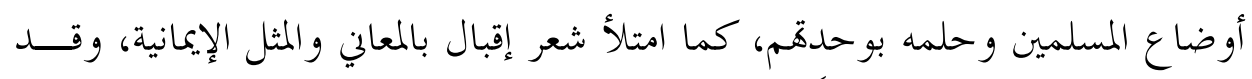

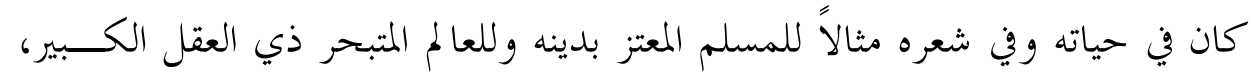

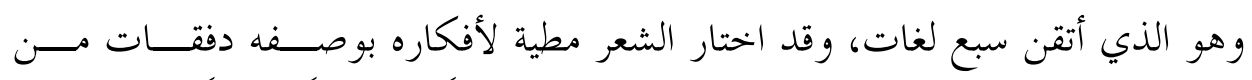

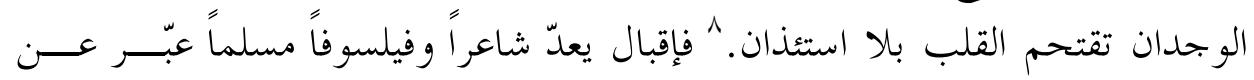

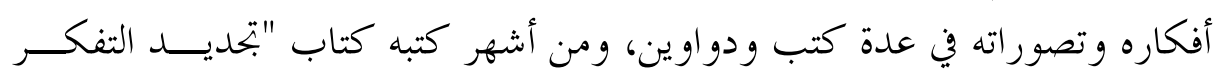

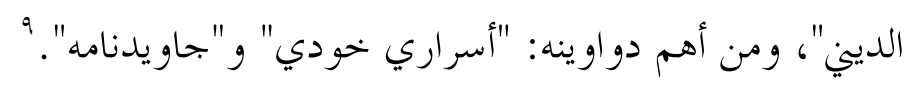

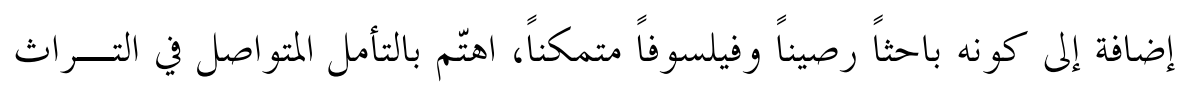

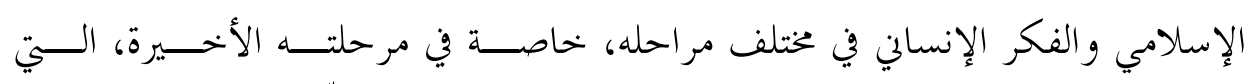

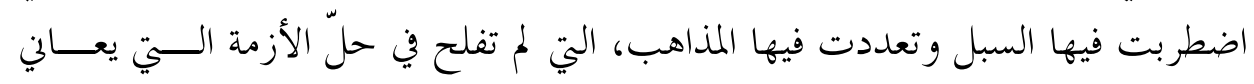
منها الإنسان المعاصر.

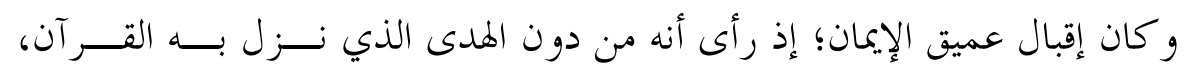

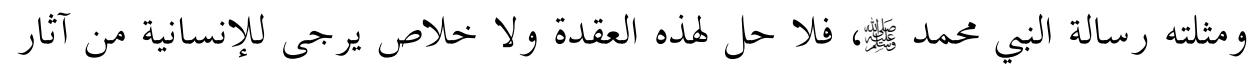

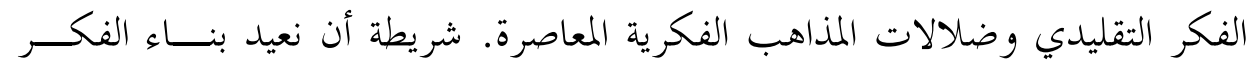

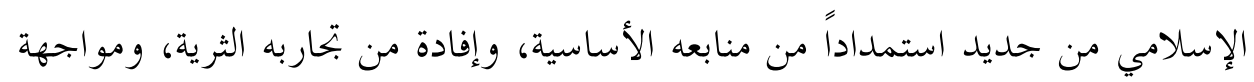

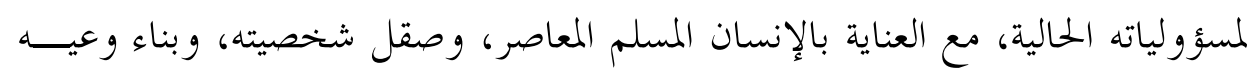
الذاتي.

ومن أكثر الأقو ال تداولاً حول محمد إقبال عبارة وصفيّة لحسن الزيـــات: "نبـــت

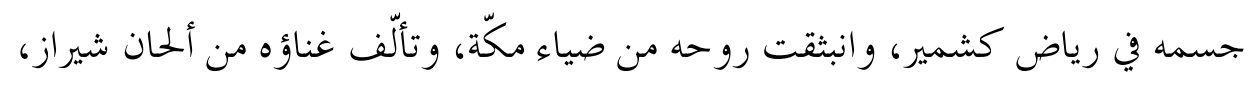

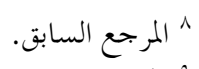

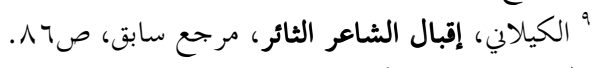

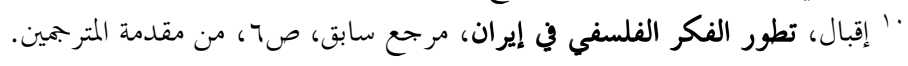




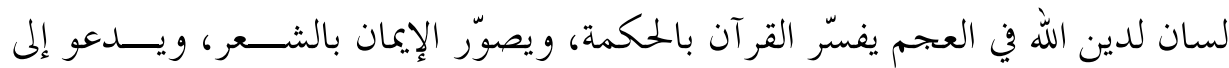

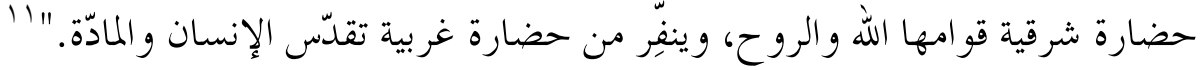

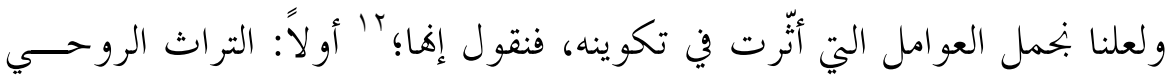
الصوي الذي هل منه على يدي والديه، ومن الحلكمة الإسلامية التي تلوّنت بتراث الهند

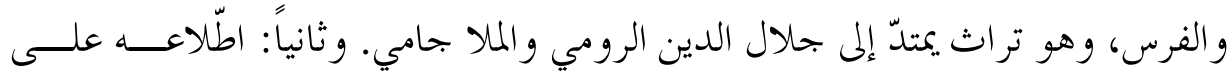

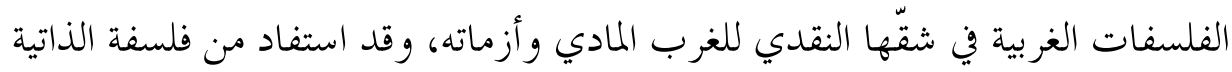

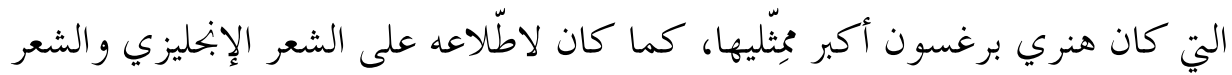

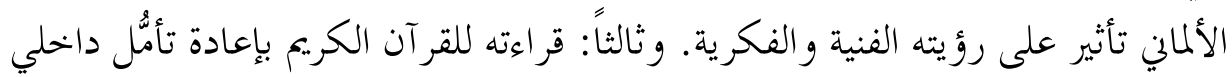

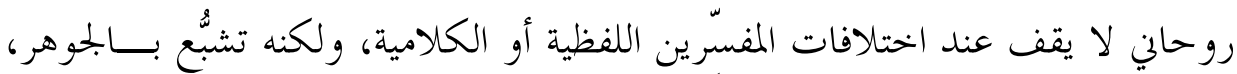
كما ورد في القصة المذكورة سابقاً مع و الده.

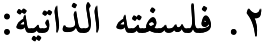

لم يكن إقبال مشتغلاً بالفلسفة وحسب كما أسلفنا، أو يهاكي فلسفات الآخرين

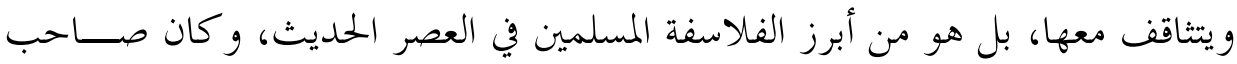

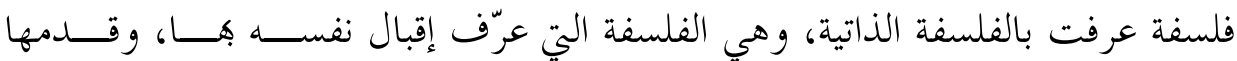

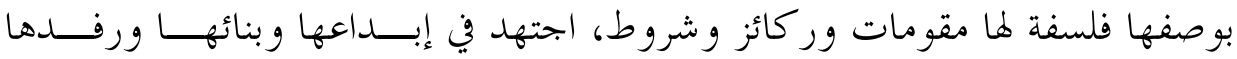

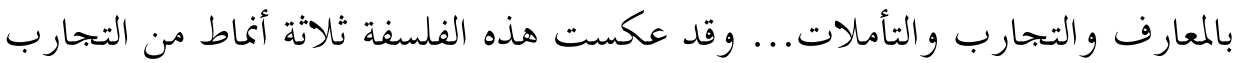

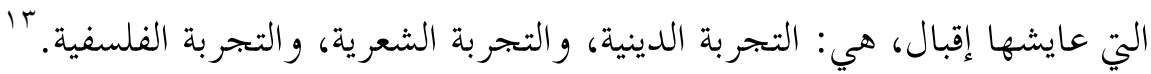

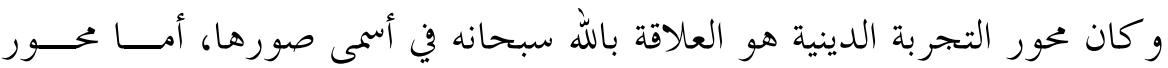

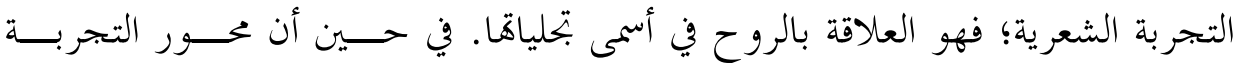

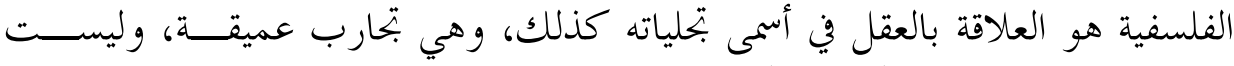

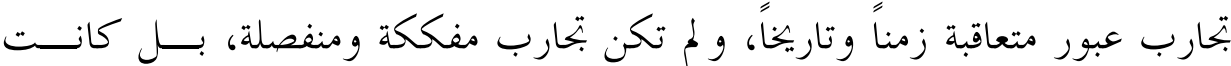
تجارب متعاضدة وراسخة.

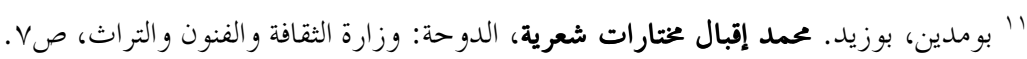

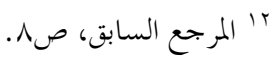

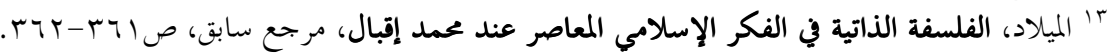

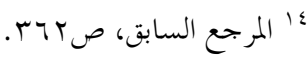


لكنه لم يكن يعطيها الدرجة نفسها، ولا يجعلها متكافئة، بل كانت التجربة الدينية

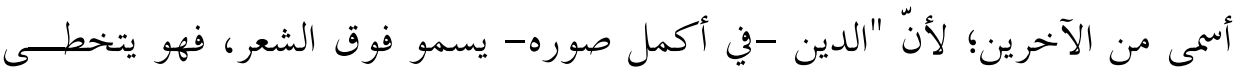

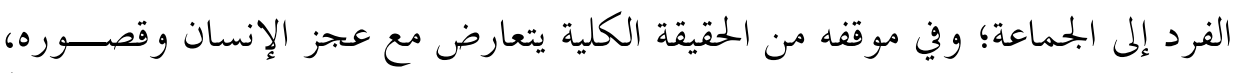

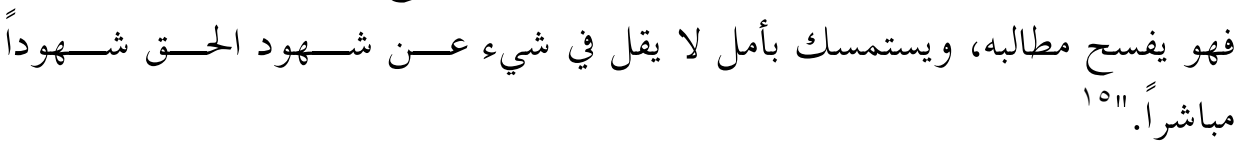

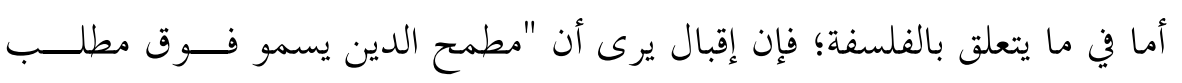

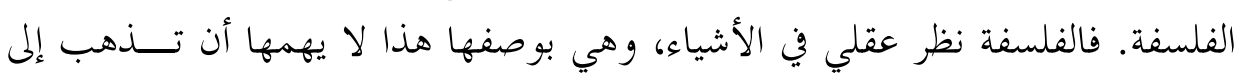

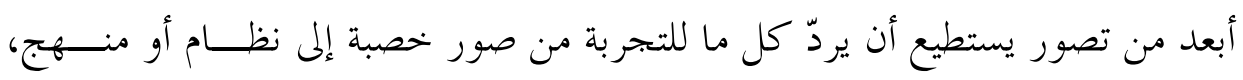

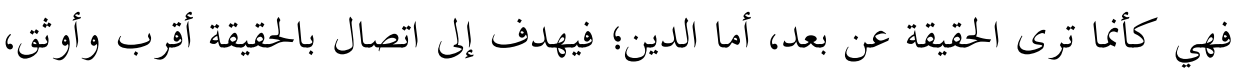

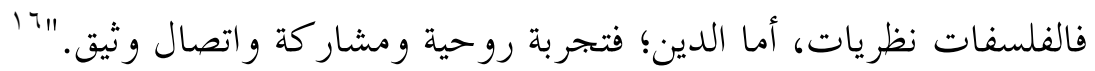
وقد لاحظ إقبال - كما لاحظ غيره من زعماء الفكر والإصلاح- أن أزمة العالم

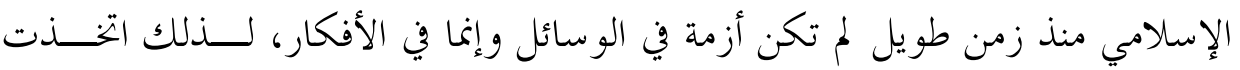

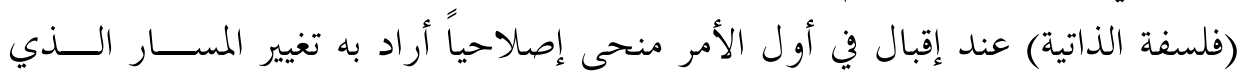

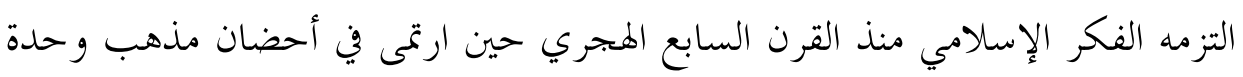

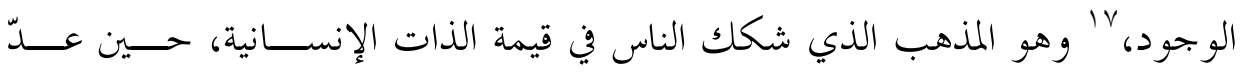

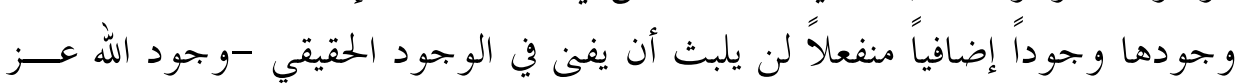

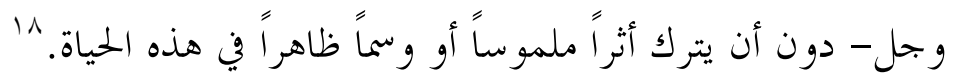

وقدّم إقبال فلسفته بشكل أساسي في مقدمتين كتبهما لاثنين من أهـــمّ دو او ينـــه

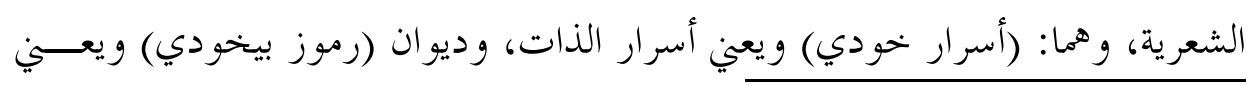

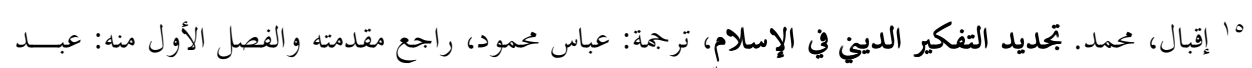

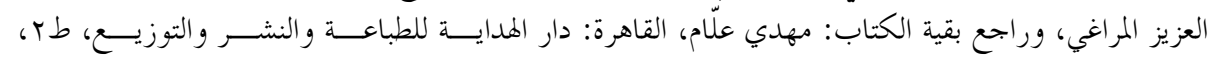

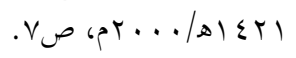

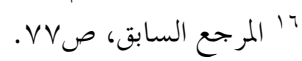

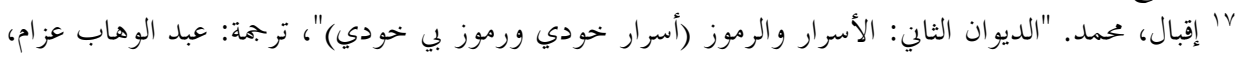

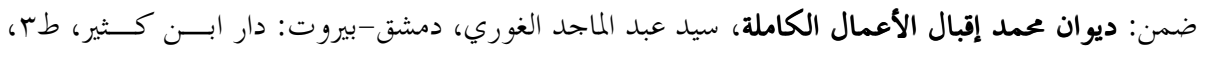

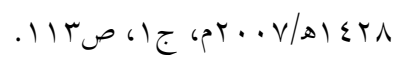

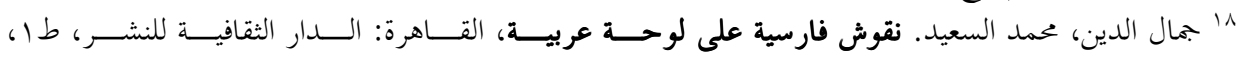

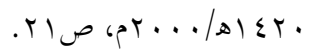




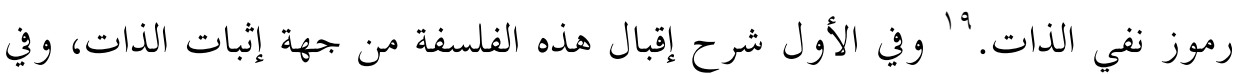

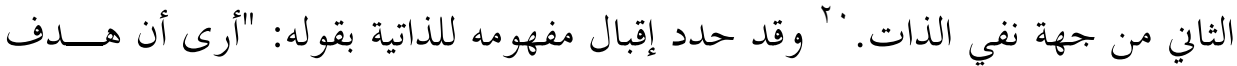

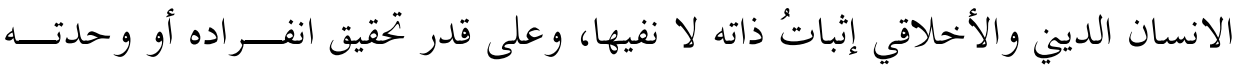
يقرب من الهدف." الانسان الدين والاقلافي

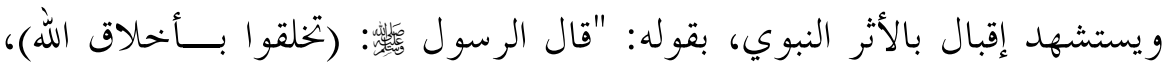

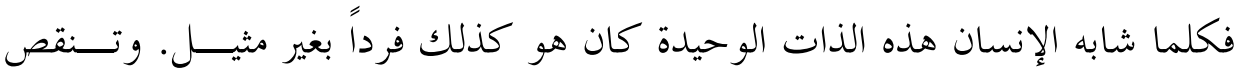

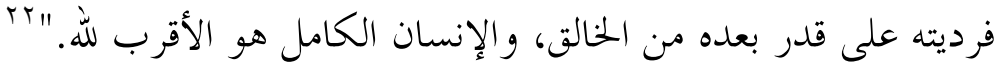

لكن إقبال الذي يحمل على فكرة وحدة الوجود بقوة - كما سنرى في الصفحات

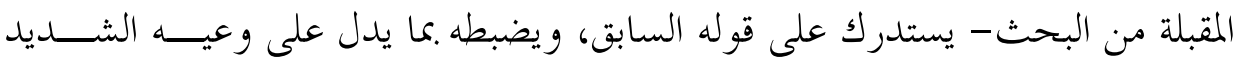

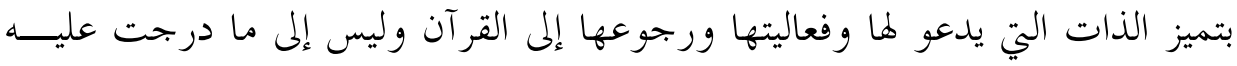

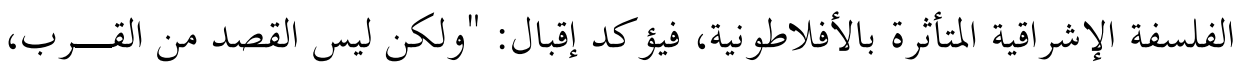

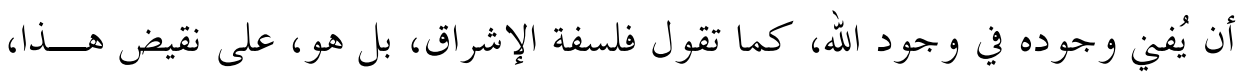

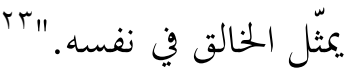

وفي هذا السياق القيمي الأخلاقي، يحدد إقبال المعنى الأخحلاقي لكلمة (خهـودي)

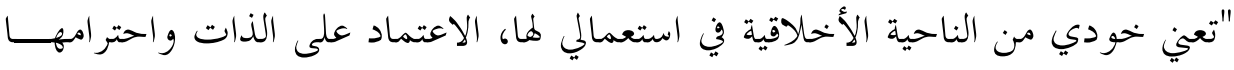

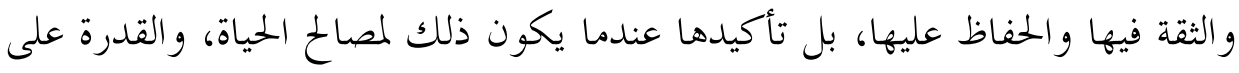

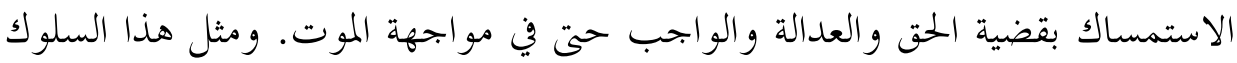

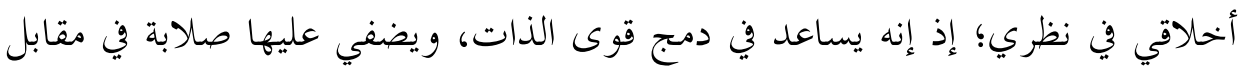

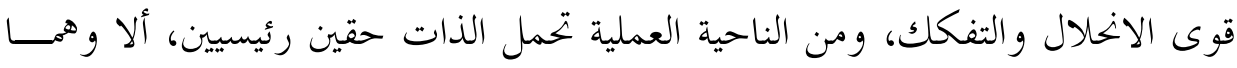

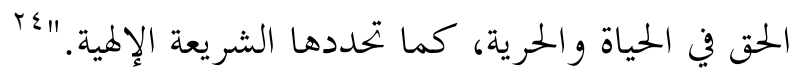

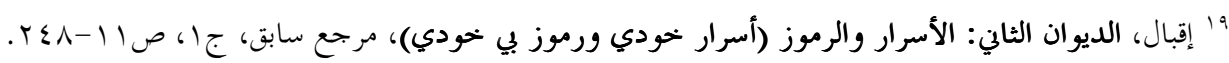

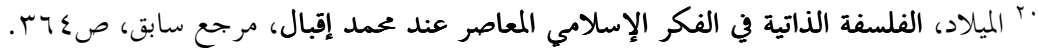

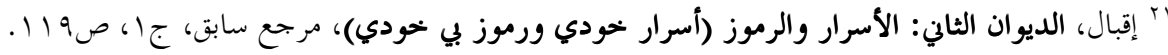

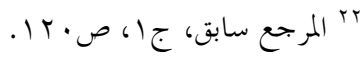

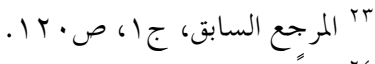

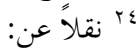
- معوض، أمد. العلّمة عممد إقبال حياته وآثاره، القاهرة: الهيئة المصرية العامة للكتاب، ـ 91 (م)، صبT. 


\section{ثانياً: تشخيصه لواقع الأمة}

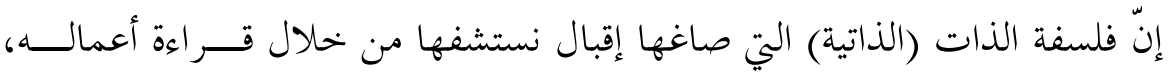

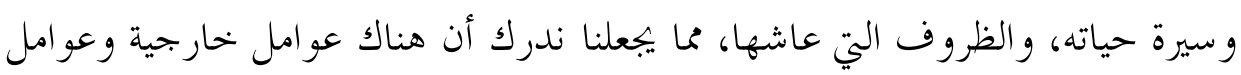

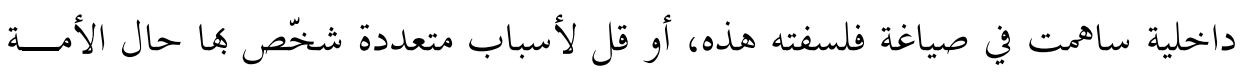
وو اقعها، وصاغة فلسفته.

لقد رأى إقبال أن العالم الإسلامي مريض بأمراض شتى؛ بعضها موروث، وبعضها

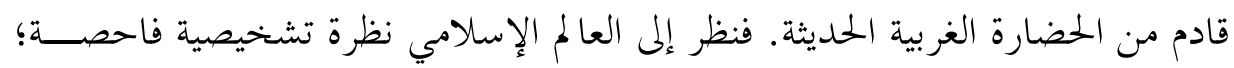

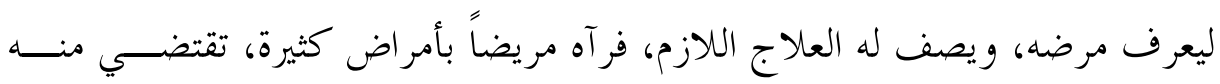

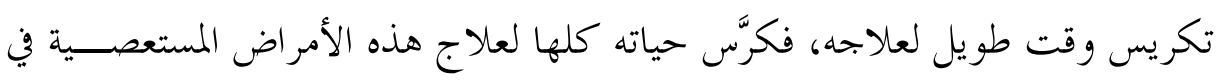
جسم العالم الإسلامي.

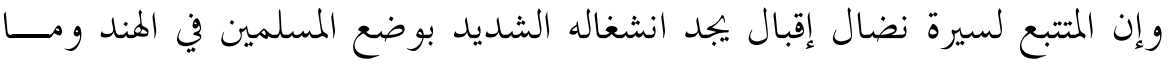

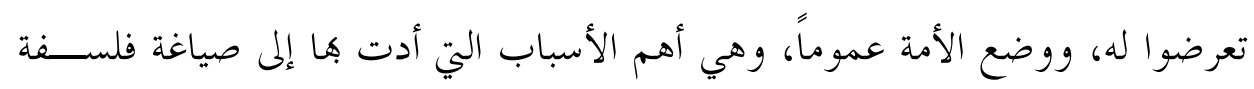

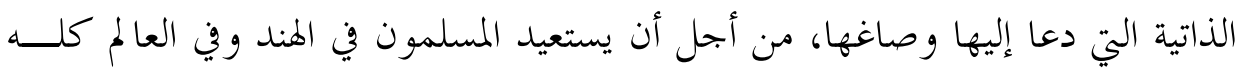
ذاتيتهم، ويخر جو ا من حالة الاستضعاف و العطالة والهامشية التي هم فيها.

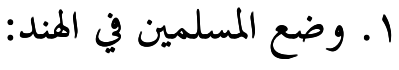

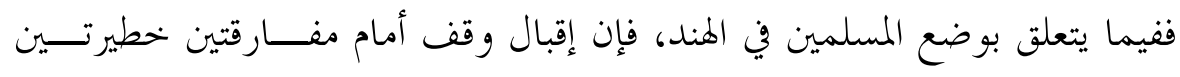

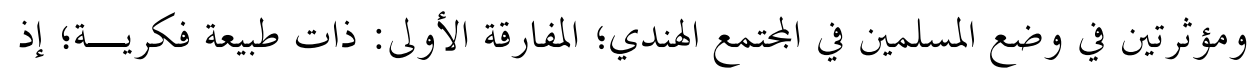

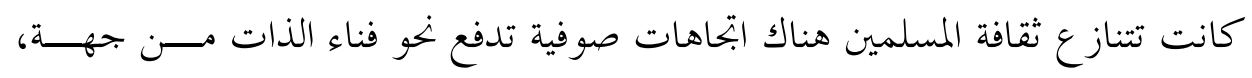

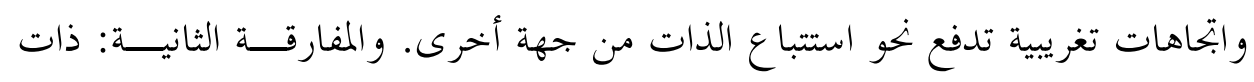

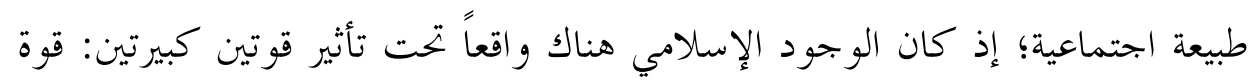

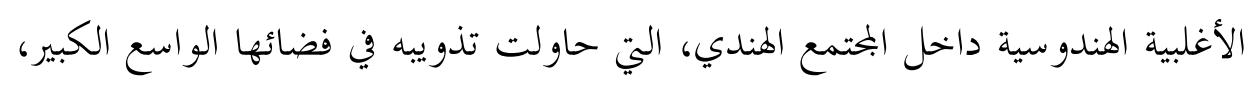

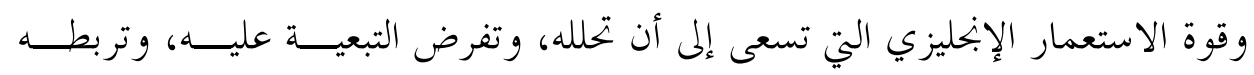




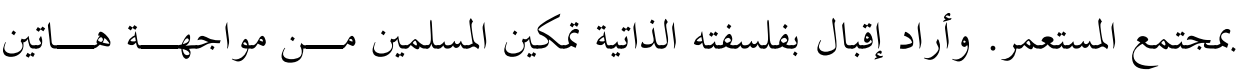
ro. القوتين.

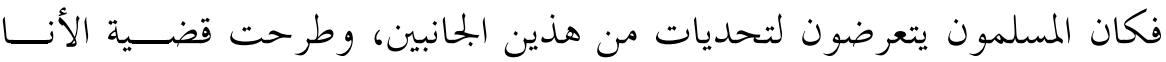

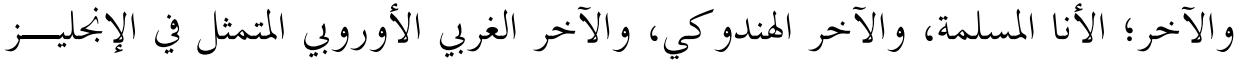

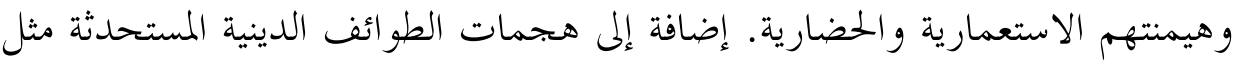
القاديانيين. فكان هذا الواقع المعاش يفرض على المفكرين المسلمين الهنود، وإقبال و واحد

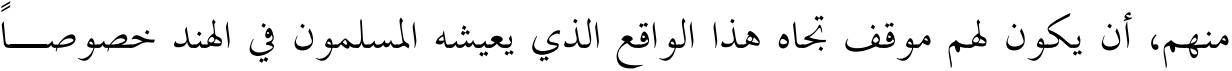

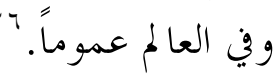

و يصوّر إقبال تكالب الجميع على المسلم في ديو انه (ضرب الكليم) بقوله:

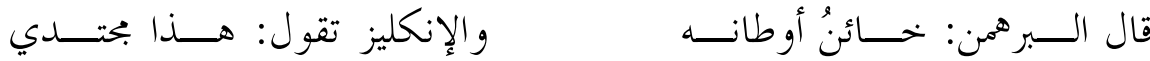
ونبوّة البنجاب قاللــت كــافر

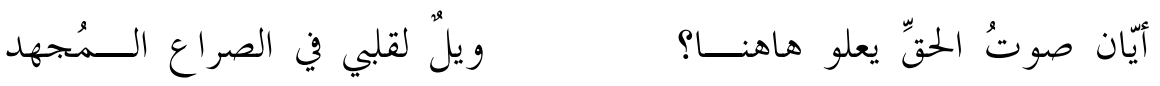
ولهذا دعا إلى قيام دولة للمسلمين في مناطق الأكثرية المسلمة في الهند، لحمايتـــهم

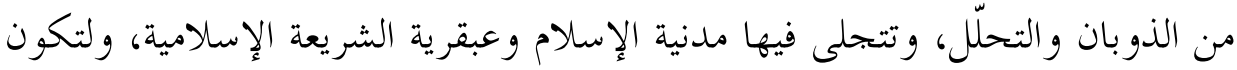

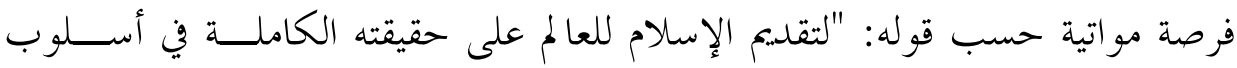

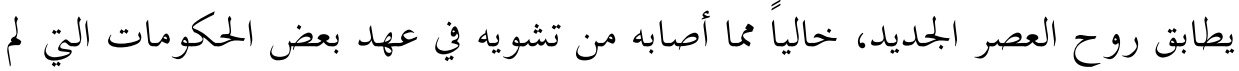

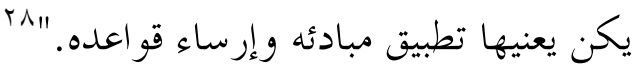

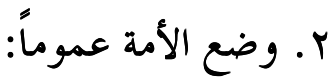

أما فيما يتعلق بصلة إقبال بأمته؛ فقد كان إقبال وثيق الصلة بالأمـــة الإســلامية؛

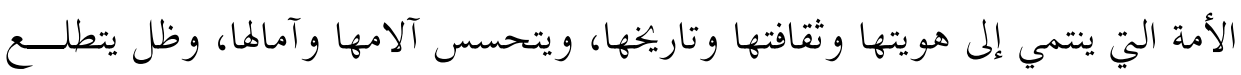

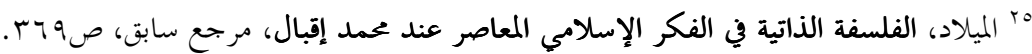

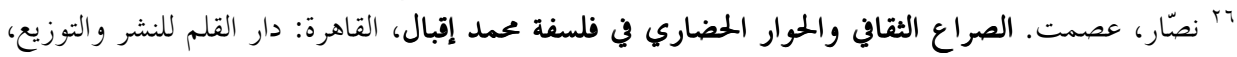

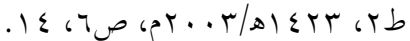

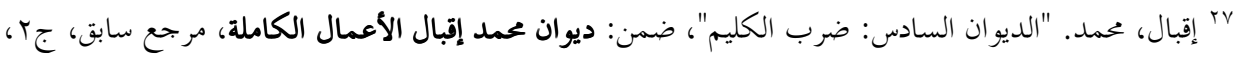
ص

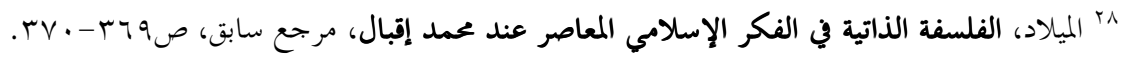


إلى اليوم الذي تستعيد فيه هذه الأمة مدنيتها وبحدها وازدهارها الحضضــاري، و شـــره و نثره ينبضان هذه الرو ح و ويتألقان بها.

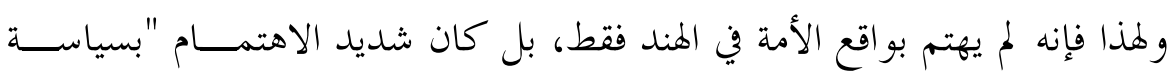
الغرب الاستعمارية في الهند بخاصة، و العالم الإسلامية بعامة، وتآمر الغرب على الخلافة العثمانية حتى سقطت، وازدياد حملات المستشرقين على العالم الإســلامي، و ازديـــاد حركات التشكيك في الدين، و التغريب و التبشير، و تعمد إذلال المسلمين عن طريـــت

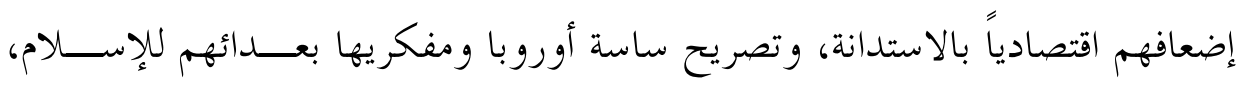
وعملهم على تقسيم أقطاره و تقطيع أوصاله.... وتفاقم الخطر الصهيولي ولا سيما بعد

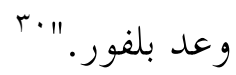

و من أهمّ ما أنشد من قصائد شخص فيها ما يعانيه العالم الإسلامي من أمـــراض،

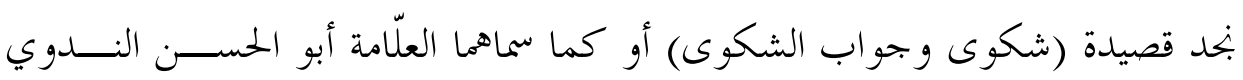

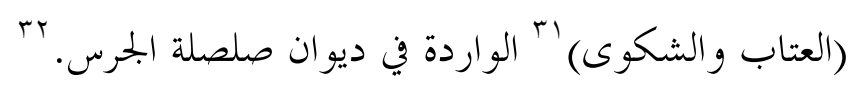

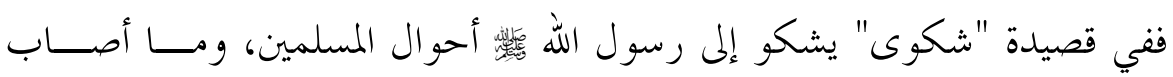
حياةم من تدهور، و مكانتهم من ضعف و اضمحلال. يقول إقبال:

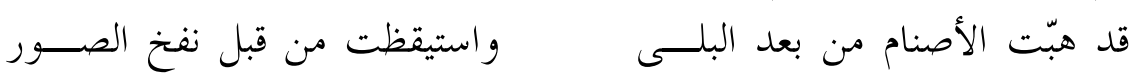

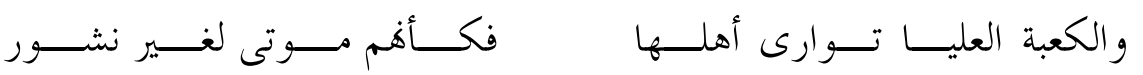

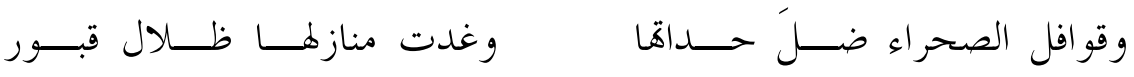

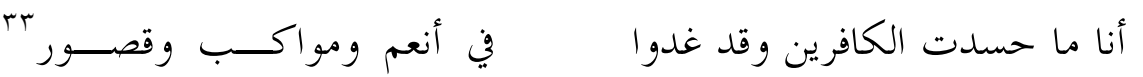

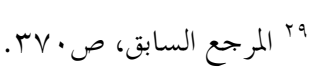

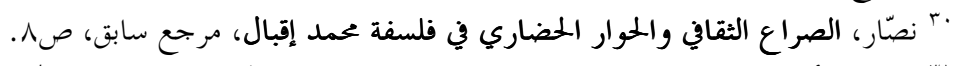

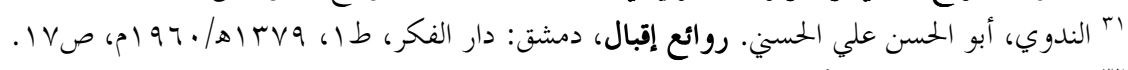

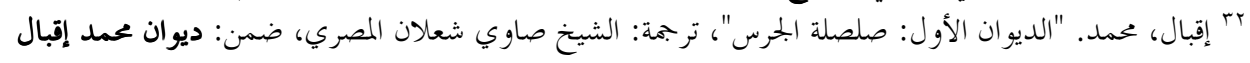

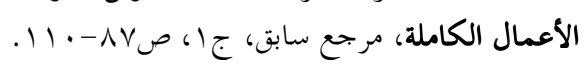

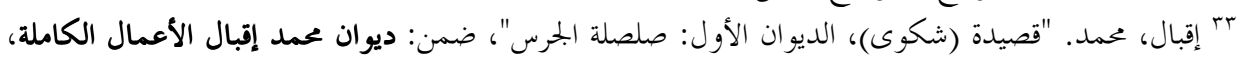


فهو يصف رجوع الجاهلية من جديد وغياب الإسلام عن قيادة حياة المســلمين،

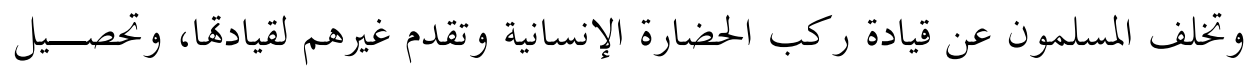

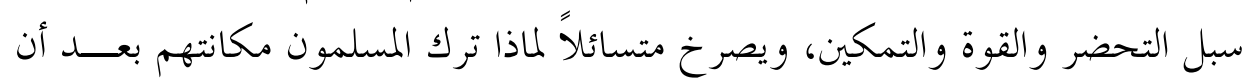

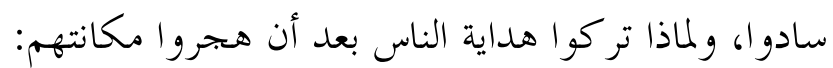

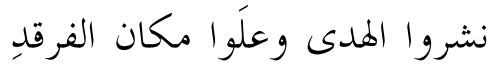
كيف انطوت أيامهم وهم الأولى

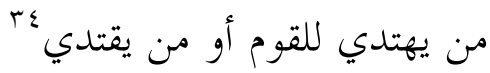
هجروا الديارَ فأين أزمعَ ركبهم

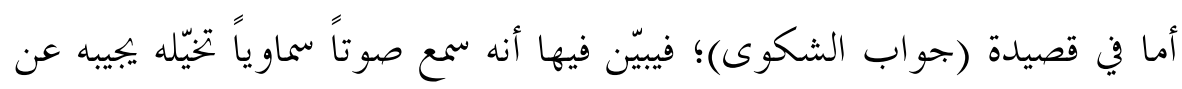

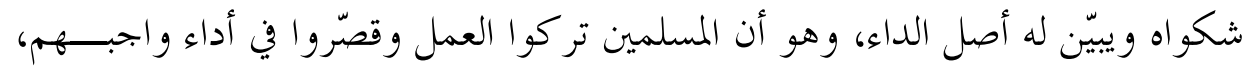

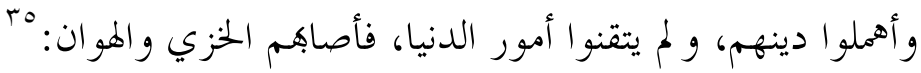

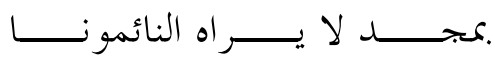

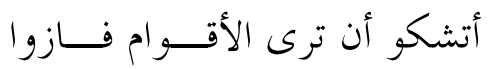

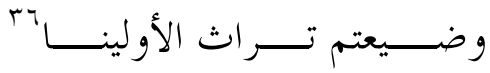

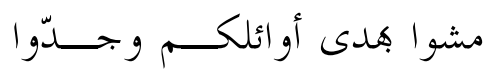
كما أنه اشتكى إهمال الأمة لرسالتها الإسلاميَّة التي جعلت منها أمَّة حية قوية في يوم ما، ويقظة الروح الجاهلية في نفوس أبنائها من جديد، فقال التهال:

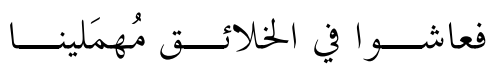

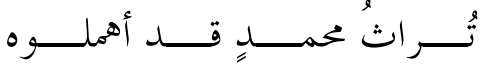

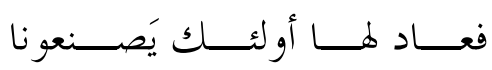

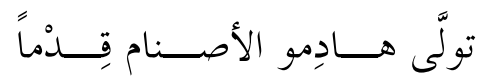

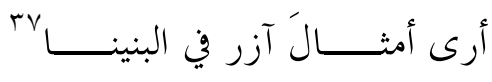

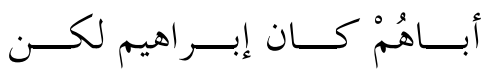
و شكى ضياع الإيمان و الدِّين و الوفاء، وشيوع الظلم وفساد الأخحلاق، فقال:

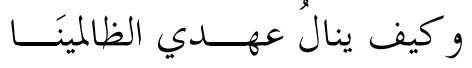

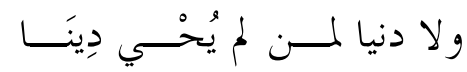

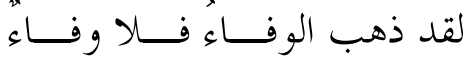

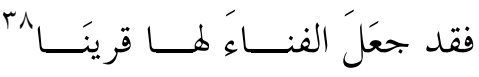

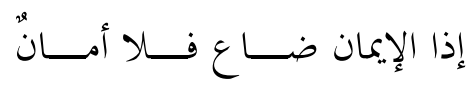
ومَن رضي الحياة بغــير ديــنٍ

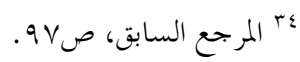

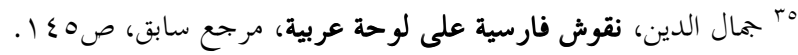

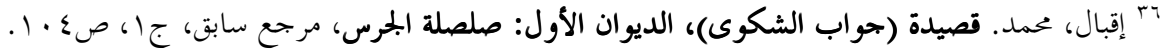

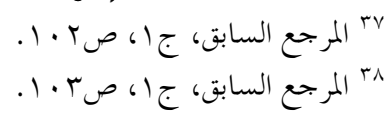




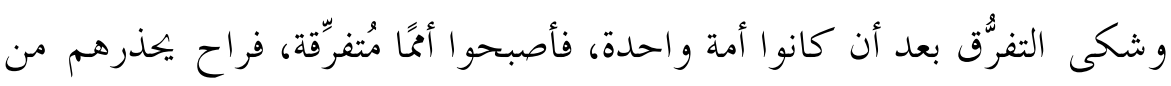

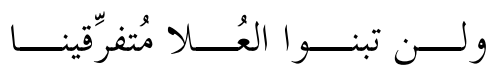

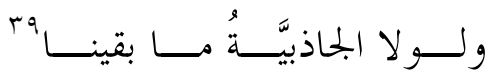
التفرق. يقول إقبال:

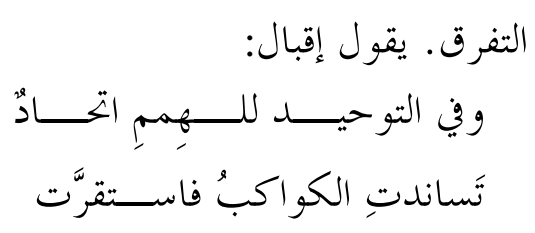

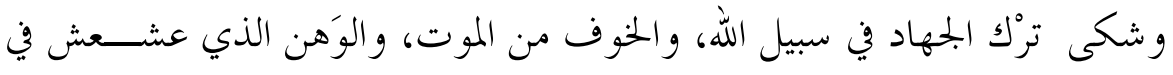

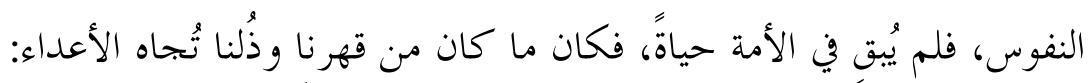

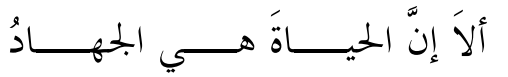

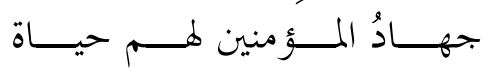

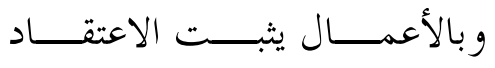

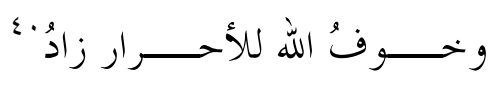

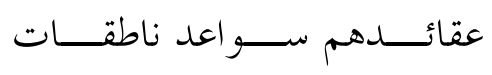
وخوفُ الموتِ للأحيــاء قَبْــرُ

هذه وغيرها من مظاهر المرض التي شخصها إقبال في الأمة، جعلتـهـ يتجــه إلى

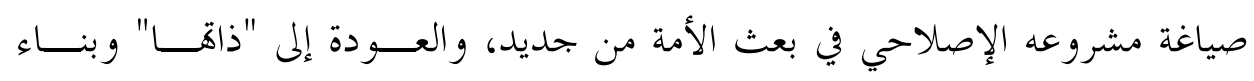

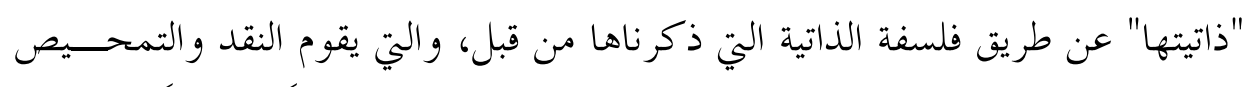

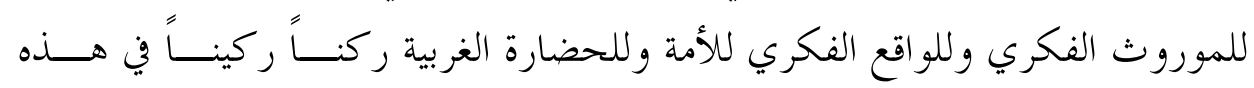
الفلسفة وهذا هو المشروع الإصلاحي.

\section{ثالثاً: المداخل النقدية}

إن التشخيص الذي قدمه إقبال لواقع الأمة، وسعيه إلى بناء ذاتية الأمة وحمايتــها

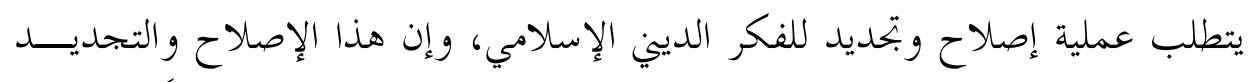

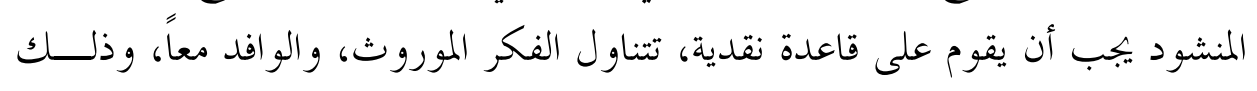

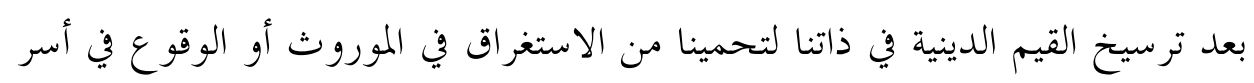

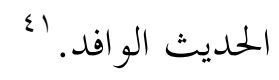

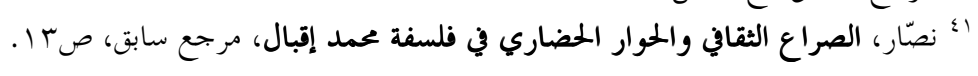


إنّ صحوتنا الحضارية تنطلق من تقويم ذاتي لمدارس الفكر الإسلامي و تياراته عــبر

التاريخ لندرك الإخفاقات التي وقع فيها و الإبحازات التي حققها، كما يتطلب التمحيص

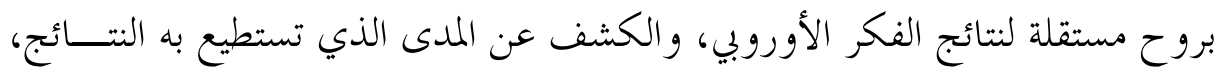

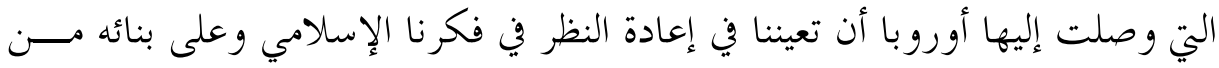

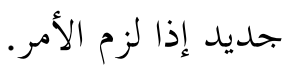

وهذا يدل - كما يرى إقبال- على أننا نختاج إلى "بناء الفلسفة الدينية الإســلامية

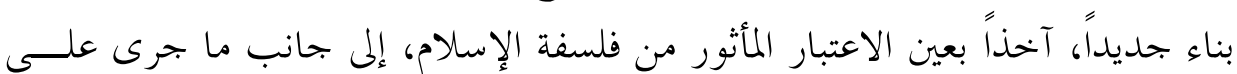

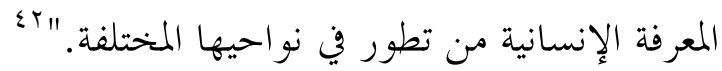

ولهذا فإن القارئ لكتب إقبال ودواوينه الشعرية، سيجد أنّ إقبال سنّ ذهاً مهماً

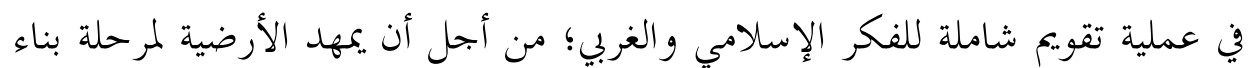
فلسفة الذاتية التي تبعث الذات الإسلامية فاعلة في التاريخ صانعة للحضارة. ولذلك بحد عنده نقداً للتراث الإسلامي، ونقداً للفكر الإســلامي في عصــوره

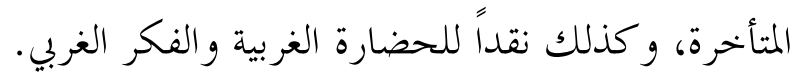

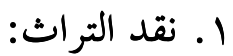

إن نقد التراث بالنسبة لإقبال تطلب منه مراجعة إبحازات التراث الفكري و الديني الإسلامي عبر التاريخ، سواء في رسالته للدكتوراه (تطور الفكر الفلســفي في بــــادلاد

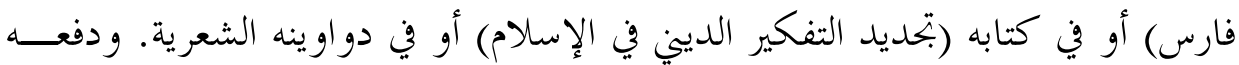
هذا الموقف النقدي إلى النظر في إبحازات الفكر الإسلامي وإخفاقاته، وإلى العوامل التي أدت إلى تلك الاخخفاقات.

أ. أثر الفلسفة اليونانية (نقد المنبهرين بالنظر الفلسفي القديم):

بالنسبة لإقبال، فإن الفكر الإسلامي استفاد من الفلسفة اليونانية بوصــفها قــوة

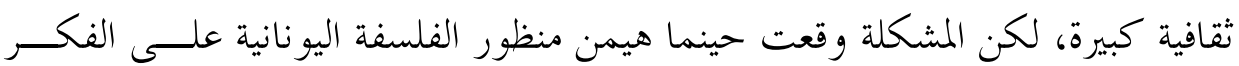
rأ إقبال، بتديد التفكير الديني في الإسلام، مرجع سابق، صع . 


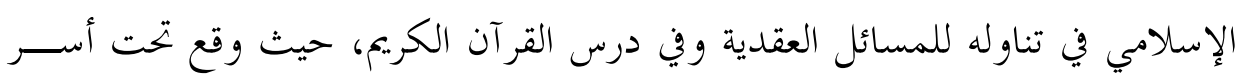

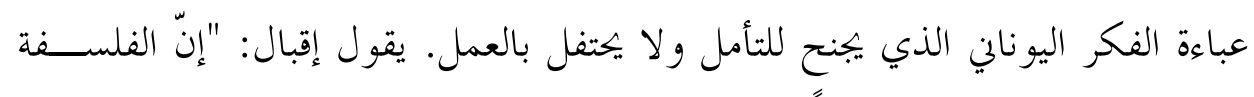

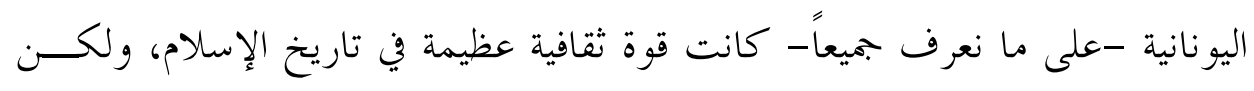

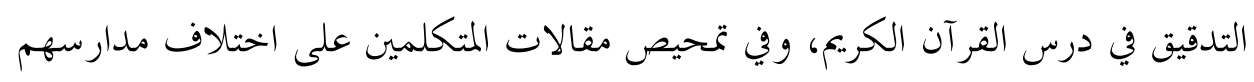

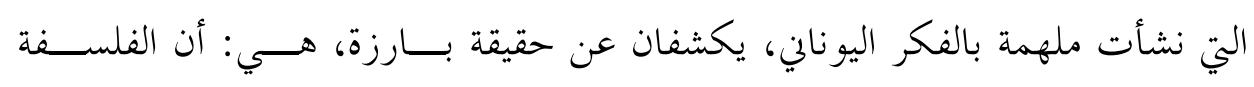

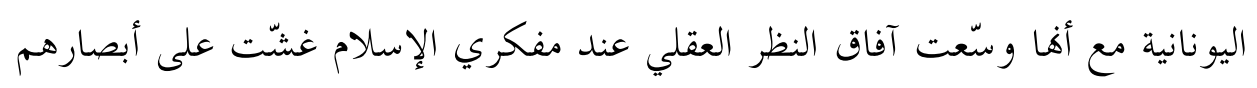

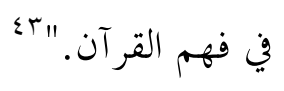

والمشكلة حسب إقبال أن سقراط، ومن بعده من تلميذ أفلاطون وغيرهما اكتفيا

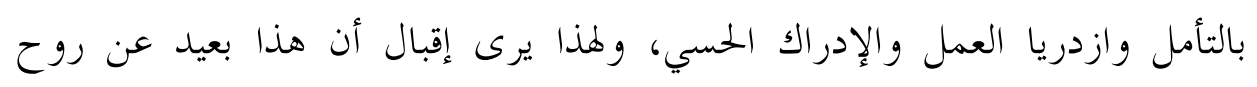

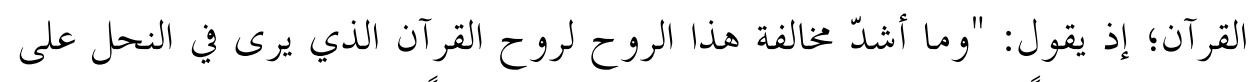

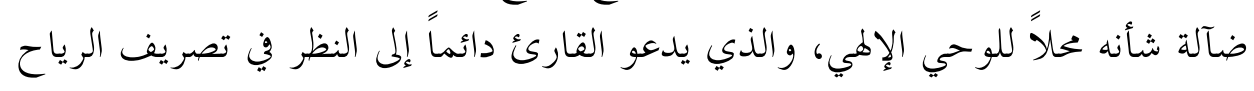

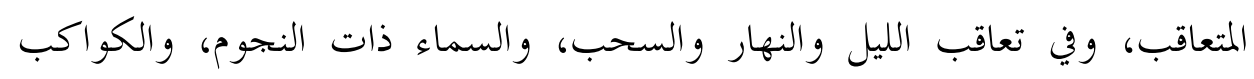

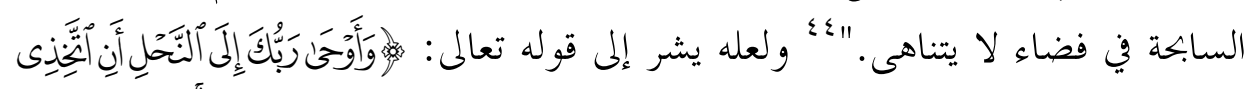

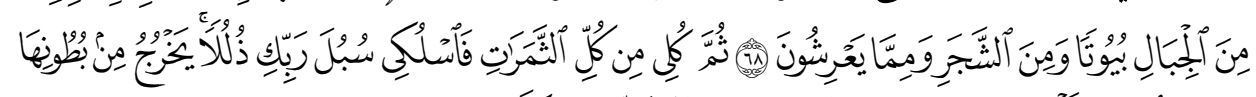

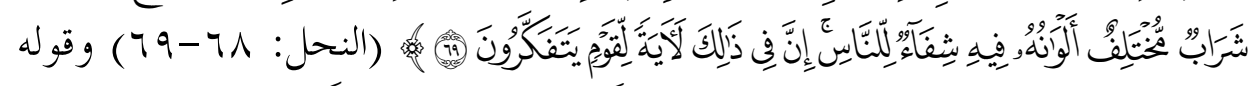

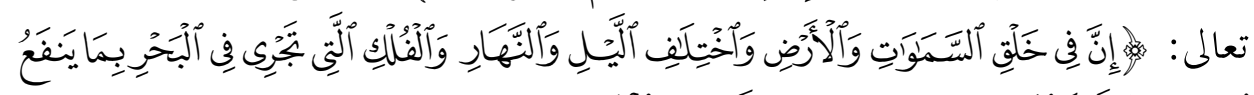

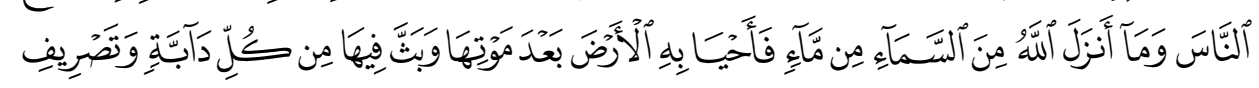

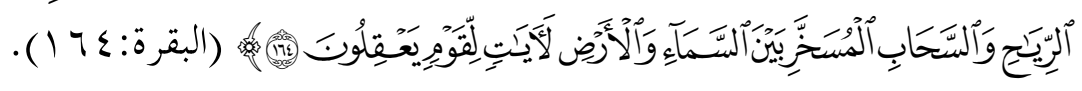

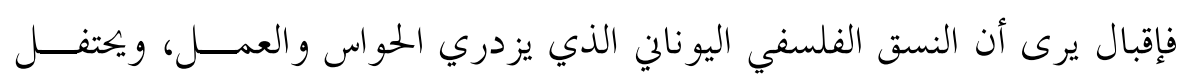

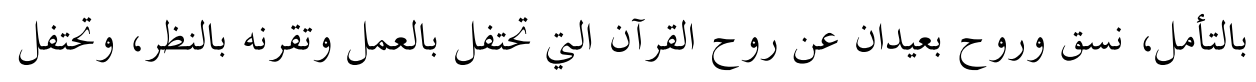
بالحس والحواس، وتمنّ على الإنسان بأن الله زوده هيدا.

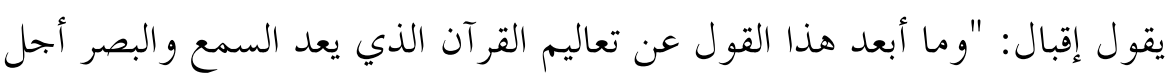

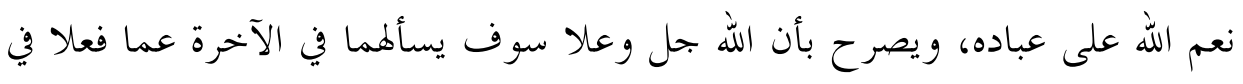

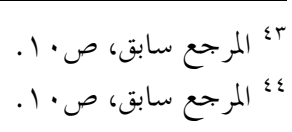




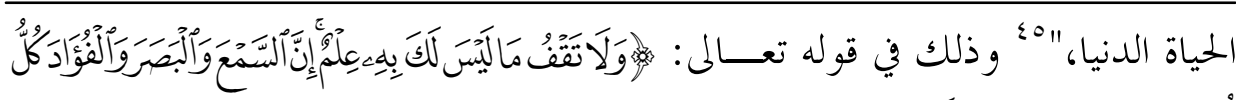

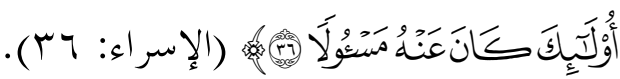

ويرى إقبال أن هذا الأمر فات على المفكرين والعلماء المسلمين الأوائل ممن افتتن

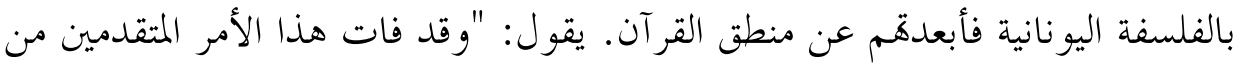

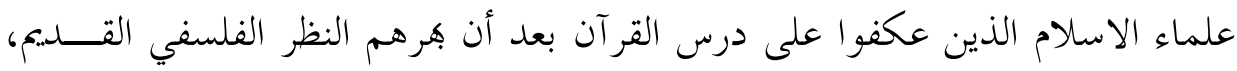

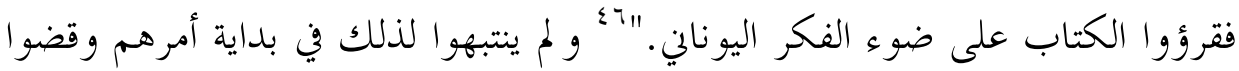

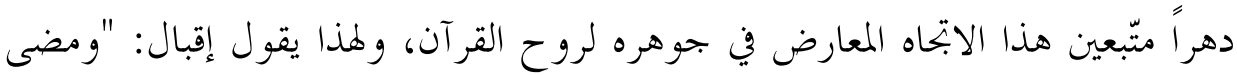

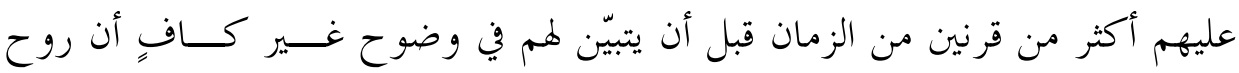

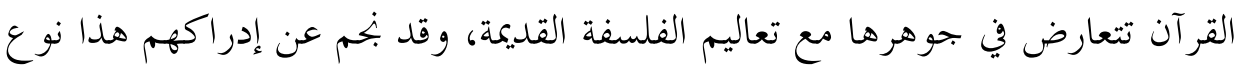

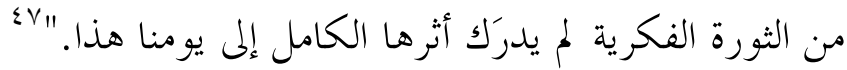

كما أن الأفلاطونية وما شاهها من الفلسفات التي تأثر هما بعض المتصوفة وفلاسفة

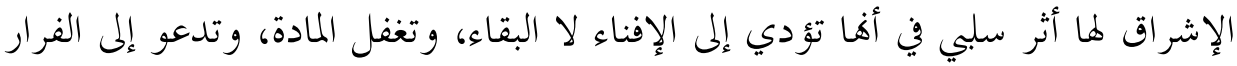

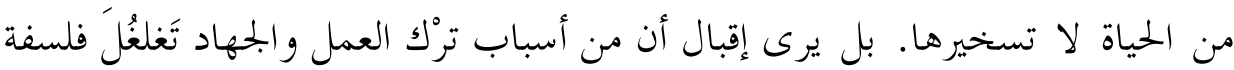

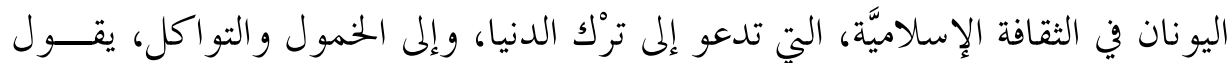
إقبال:

من فريق الضأن في الدهر التــــيمْ

في حزون الكون قد أعيا وكــلَّ

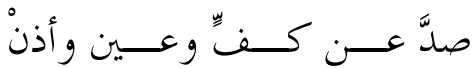
في خمودِ الشمع يسـزداد ســناهُ

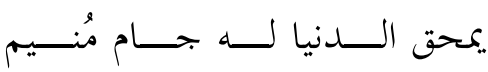
وهْو في الصوفي ذو بأسٍ قــوي
راهبُ الماضين أفــلاط الحكــيم

طرفه في ظُلمة المعتـــــل ضــل

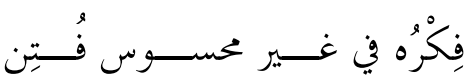

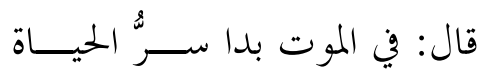

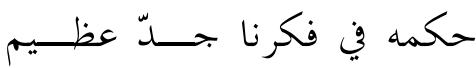

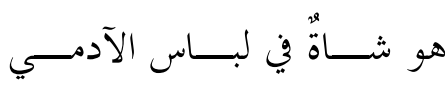




$$
\begin{aligned}
& \text { عــــا لم الأشــــاء سمــــاه الهــــراء }
\end{aligned}
$$

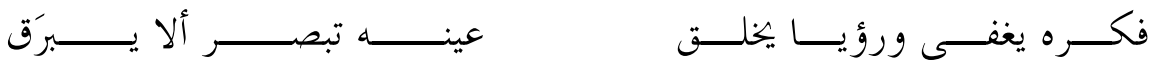

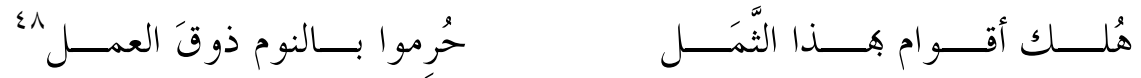

يقول إقبال: "و اعتراضي على أفلاطون، هو في أصله اعتراضٌ على كل الـــنظم الفلسفية التي تقصد إلى الفناء، لا البقاء، والتي تُغفل المادة، وهي أكبر العقبات في سبيل

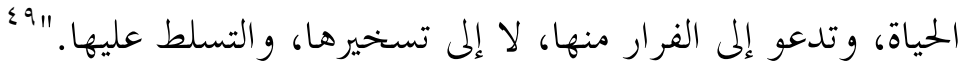

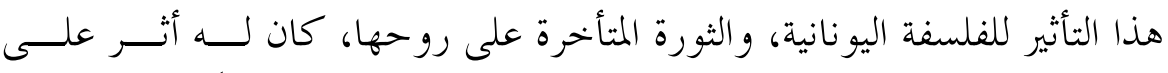

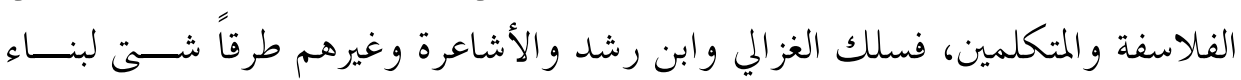
الفكر الإسلامي، مما كان له آثاره الإيجابية و السلبية إلى اليوم.

فبالنسبة للغزالي يرى إقبال أنه "كان من نتائج هذه الثورة من ناحيــة، وبتــأثير

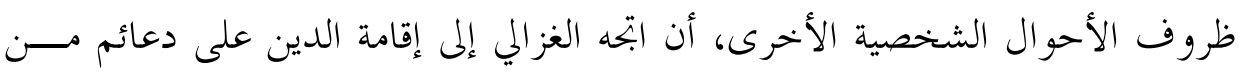

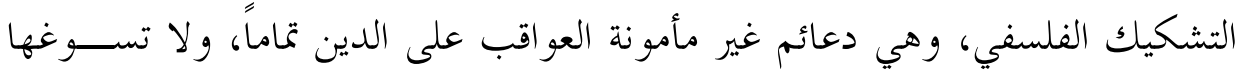

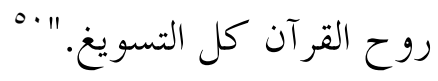

أما بالنسبة لابن رشد؛ فيرى إقبال أنه أهدر النظرة القرآنية لقيمة النفس الانسانية

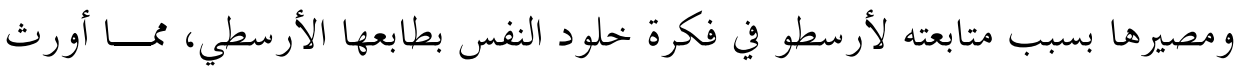

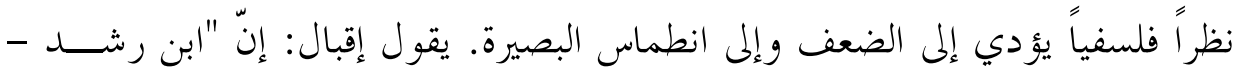

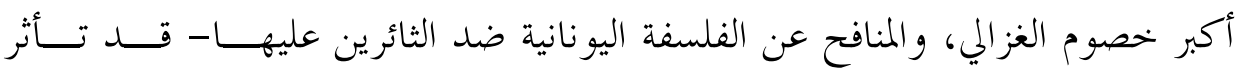

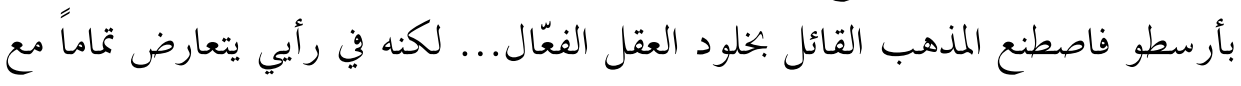

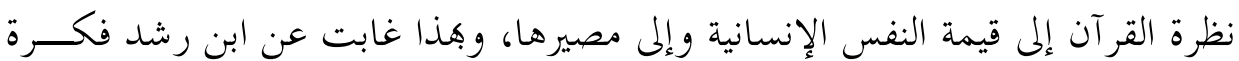

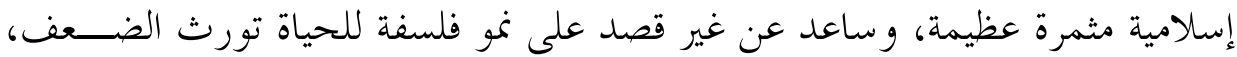

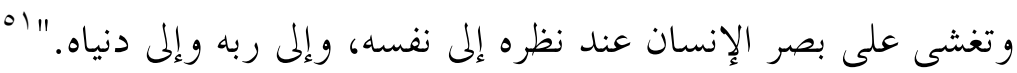

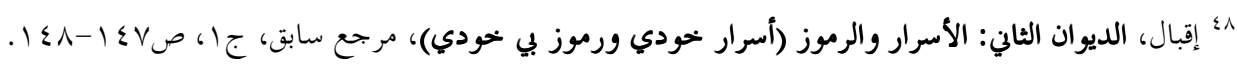

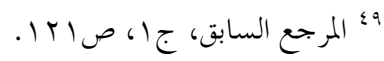

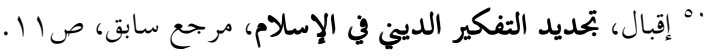

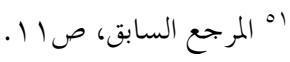




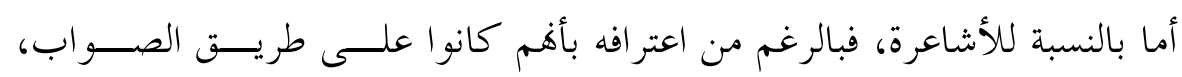

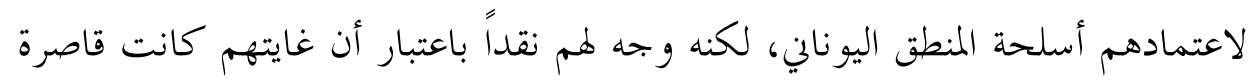

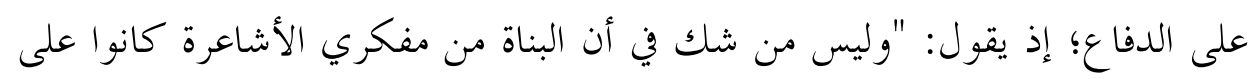

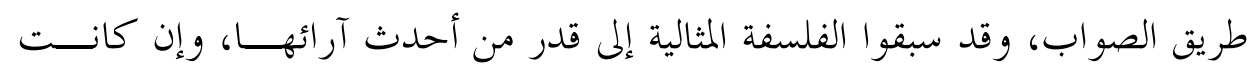

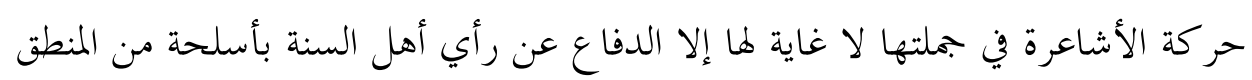

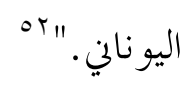

أما المعتزلة فمشكلتهم في أهم اختزلوا الدين في نسق من العقائد؛ نسق من المعاني المنطقية انتهت إلى موقف سلبي، لعله يذكرنا بالنقد الذي و جهه متكلمو أهل السنة إلى

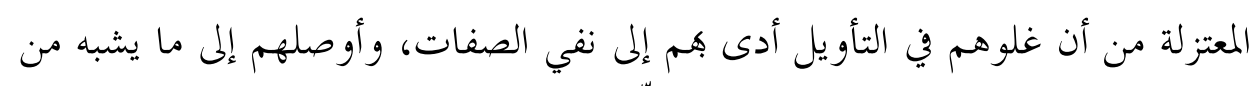

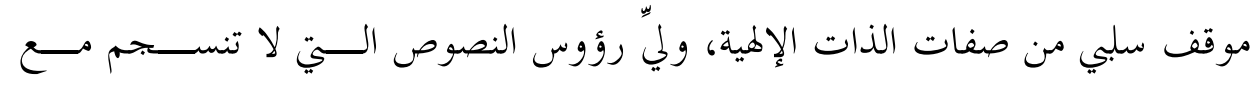
مسلماهم العقلية.

يقول إقبال: "أما المعتزلة فقد قصروا إدراكهم للدين على أنه بحموعة من العقائد،

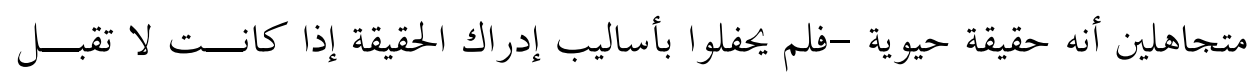

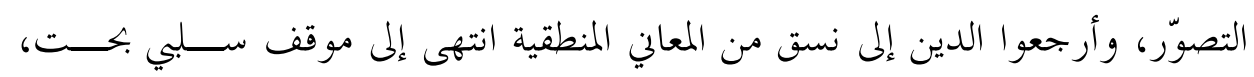

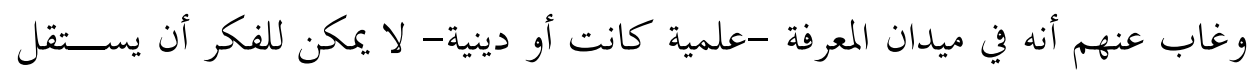

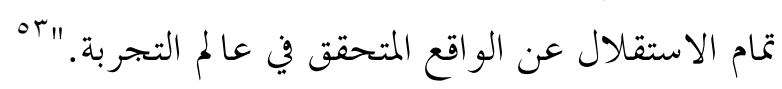

كما أن إقبال يتعجب من ابخرار الفلاسفة والمتكلمين وراء اصطلاحات الفلســفة

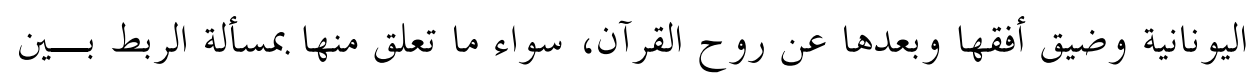

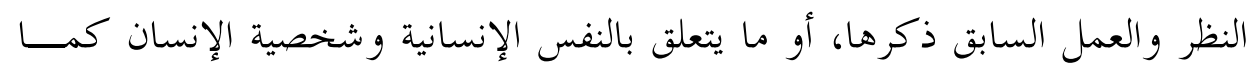
أكد عليها القر آن.

و في سياق نقده لابخرار الفكر الإسلامي وراء تحديدات ماهية النفس في الفلســفة

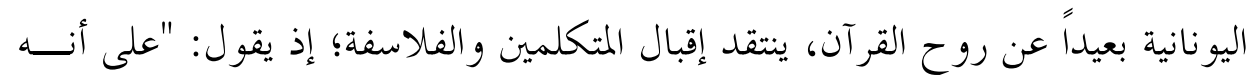




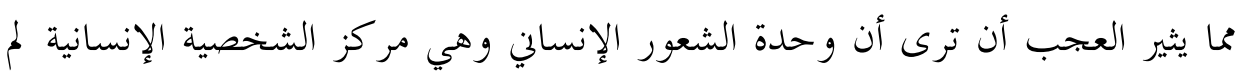

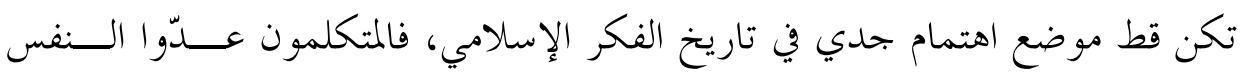

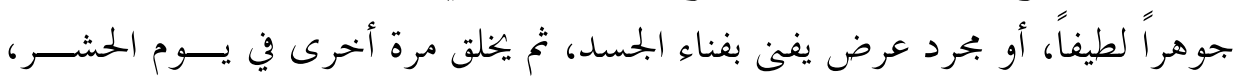

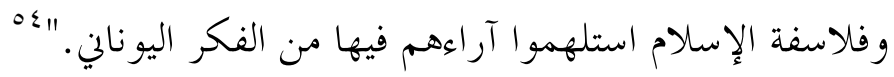

\section{ب. ثورة الفكر الإسلامي على الفلسفة اليونانية:}

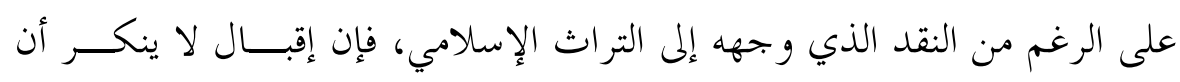

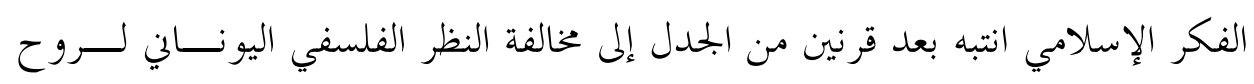

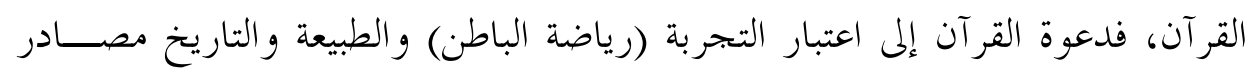

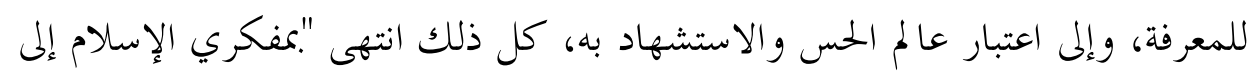

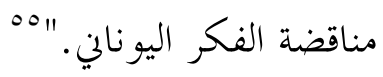

ولكن بعد أن قضوا زمناً في الافتتان به، حيث إفم "أقبلو ا في بــاكورة حيــاهم

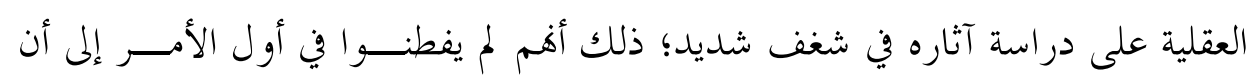

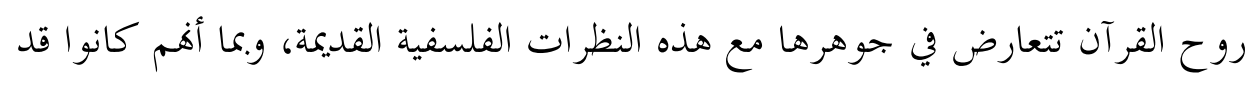

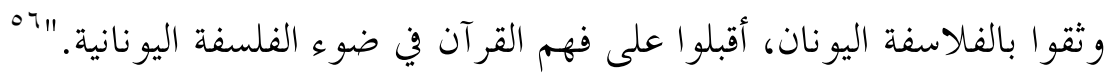
و كان الإخفاق سببه أن "روح القرآن تتجلى فيها الروح الو اقعية، علـى حسين الفين

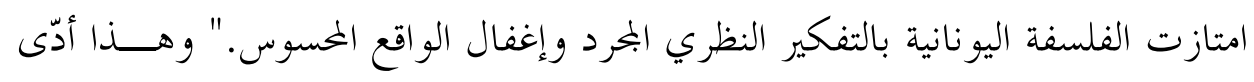

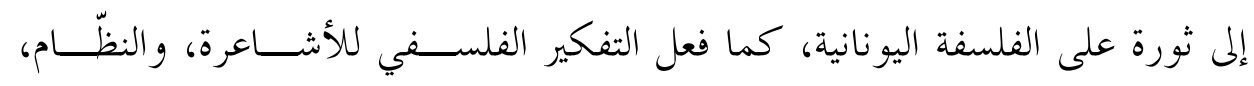

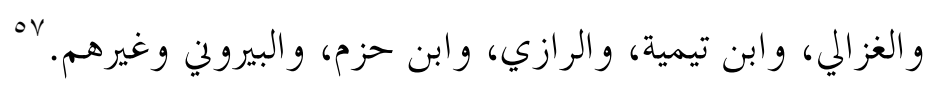

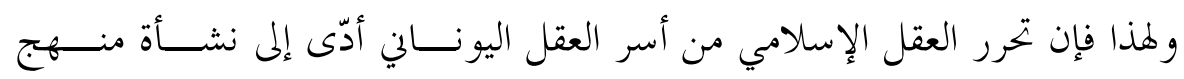

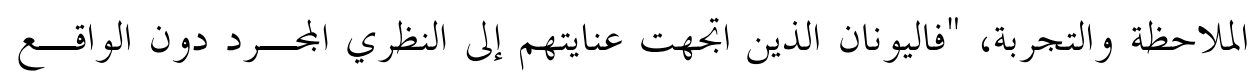

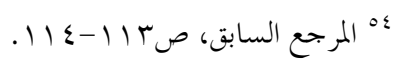

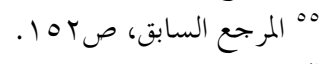

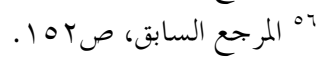

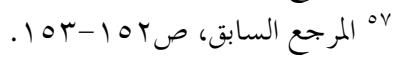




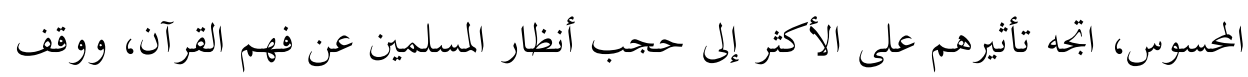

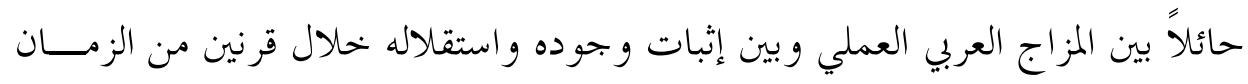

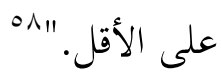

ولهذا يرى إقبال أن طبيعة الثقافة الإسلامية مختلفة عن طبيعة الثقافــة اليونانيــة،

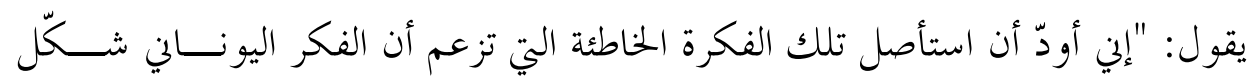
طبيعة الثقافة الإسلامية." مونه

\section{r. إنقد ركود الفكر الإسلامي المتأخر:}

كما توجه إقبال بالنقد لتأثير الفلسفة اليونانية للفكر الإسلامي القـــيم وإصــابته

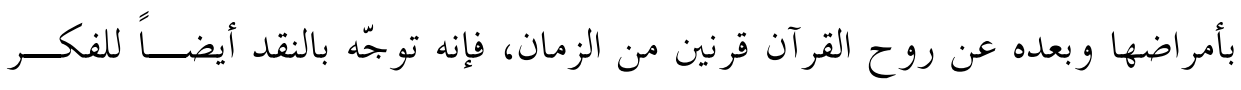

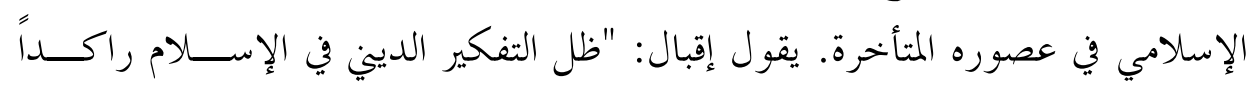

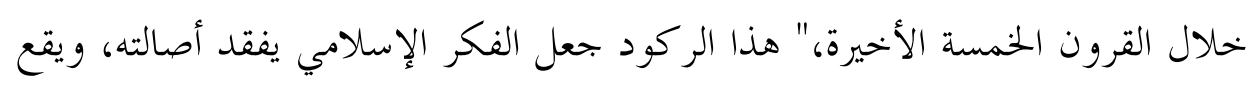

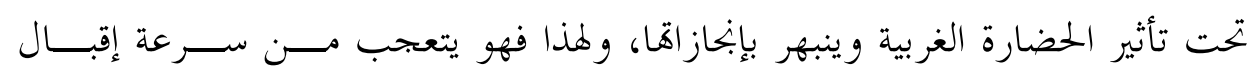
المسلمين على هذه الحضارة.

ونعى إقبال على المسلمين جمودهم على القديم وتقصيرهم في الإبداع و الابتكــار.

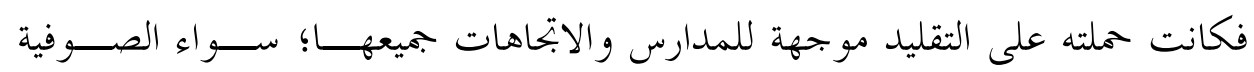

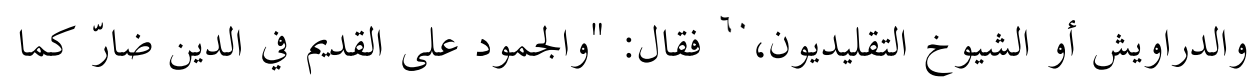

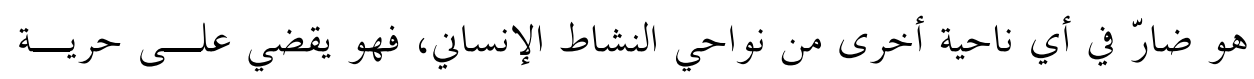

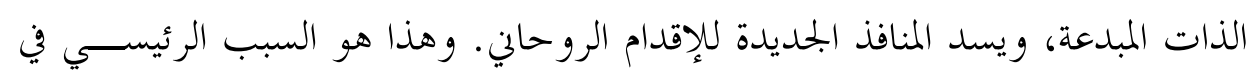

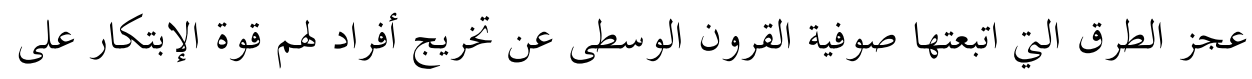

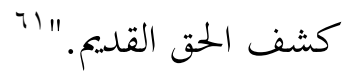

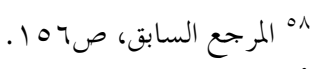

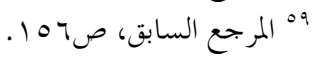

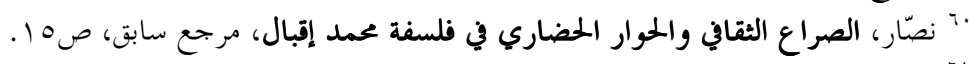

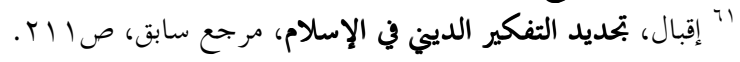


وهذا ما جعل أبناء المسلمين في العصور الحديثة يسارعون إلى تقليد الغرب، يقول

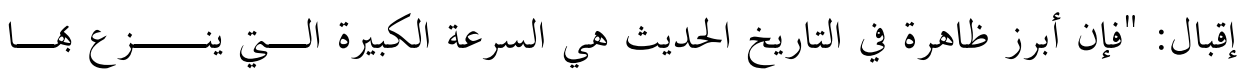

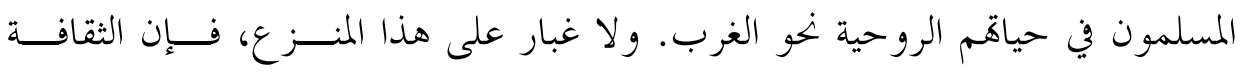
الأوروبية في جانبها العقلي ليست إلا ازدهاراً لبعض الجوانب المهمة في ثقافة الإسلام.

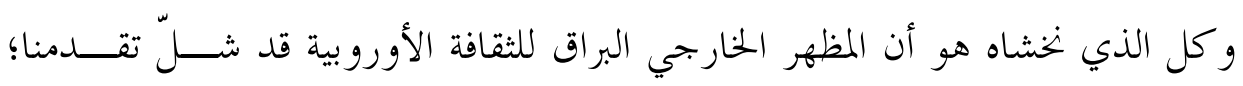
فنعجز عن بلو غ كنه ولها و حقيقتها.

كما ينتقد إقبال متأخرة الصوفية والتصوف المتأخر، ويرى أنه صار عاجزاً وفقـــــ

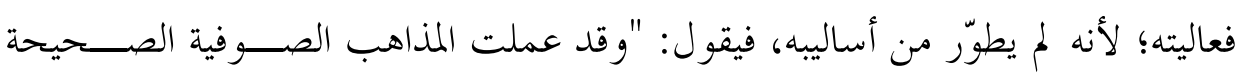

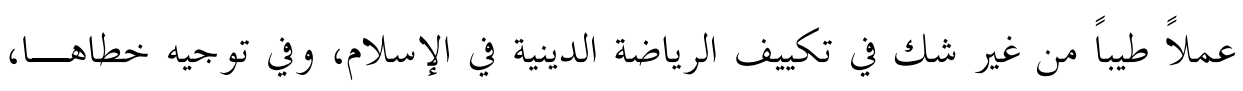

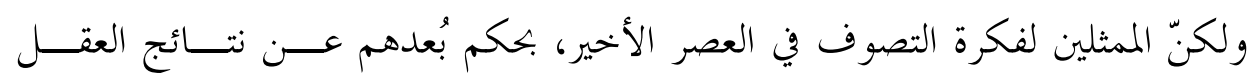

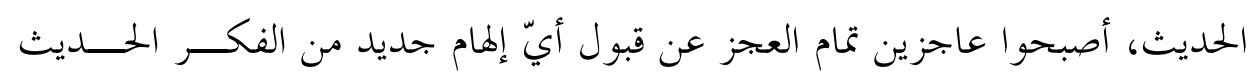
و التجربة العصرية. وهم يزاولون أساليب خلقت لأجيال كانت لها نظرة ثقافية تختلف إنف

$$
\text { عن نظرتنا نحن في نواح مهمة." }
$$

بل إنّ "هذه الروح التي طبع هـا التصوف في عصوره الأخيرة حجبت أنظار الناس

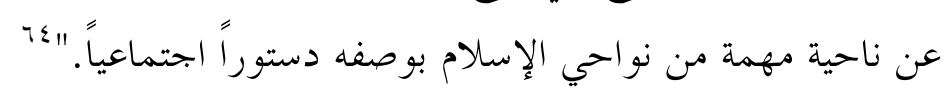

ولهذا لاحظ إقبال - كما لاحظ غيره من زعماء الفكر والإصالح- أن أزمة العالم الإسلامي منذ زمن طويل لم تكن أزمة في الوسائل وإنما في الأفكار، لذلك اتخذت هذهاء

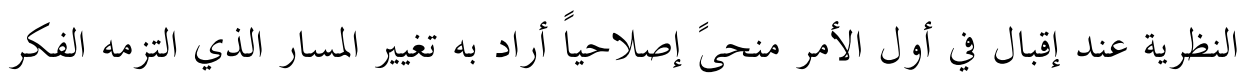

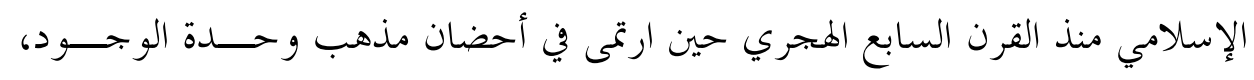

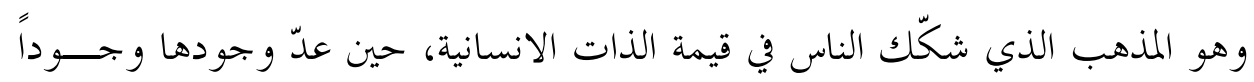

$$
\begin{aligned}
& \text { rآ المرجع السابق، صه } 1 \text {. }
\end{aligned}
$$

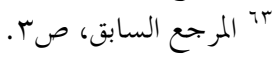

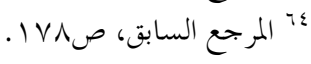




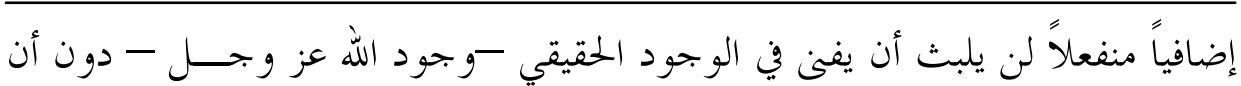
يترك اثراً ملموساً أو وسماً ظاهراً في هذه الحياة.

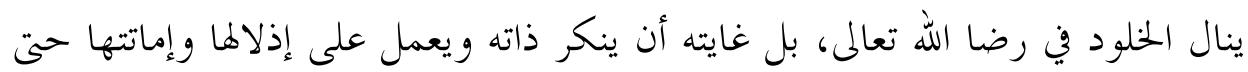
تؤهل للفناء في الله، كما تفنى القطرة في البحر. و لم يقف الأمر عند المفكرين والأفراد من الناس، بل انتقلت مقــــولات مــــهب

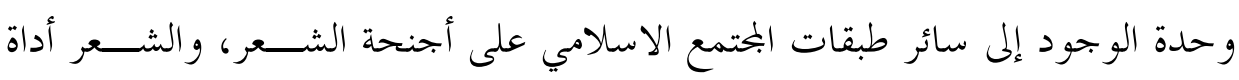
خلّابة تفعل الأعاجيب بالإنسان. وقد اتخذه الصوفية - من أصحاب وحدة الصابل الوجود -

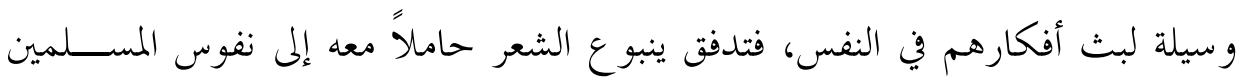

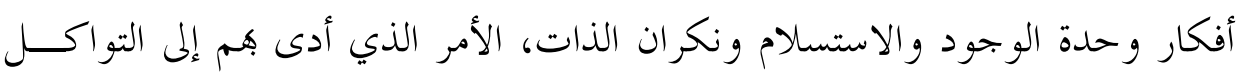
وسقوط الهمة، و ازدراء العمل وتحقيره.

\section{r. نقد الحضارة الغربية: - ن}

\section{أ. في الصلة بالحضارة الغربية:}

يعدّ العلّامة إقبال أحد روّاد التجديد الإسلامي الذين انتقدوا الحضـــارة الغربيـــة

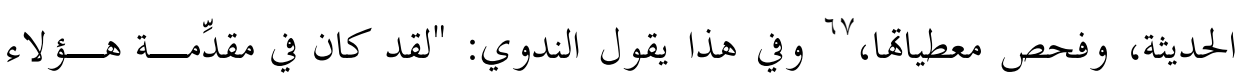

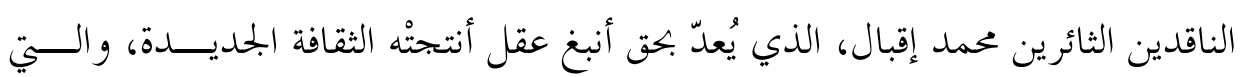

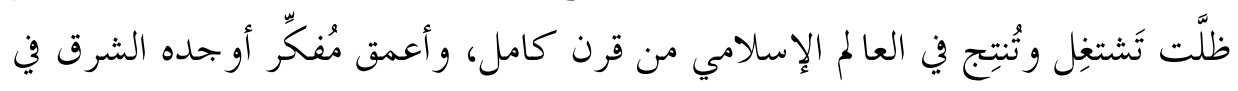

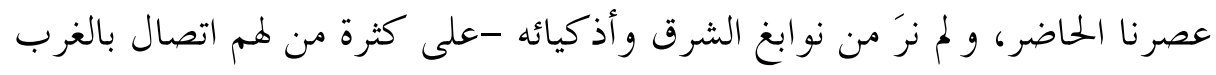

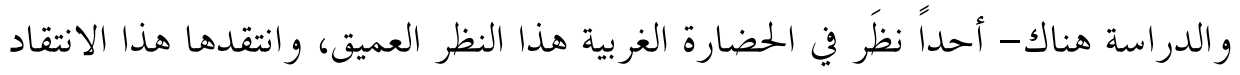

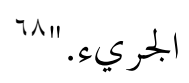

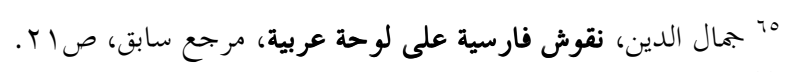

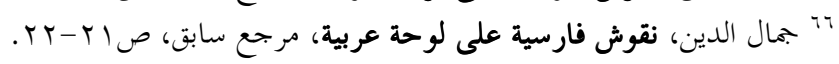

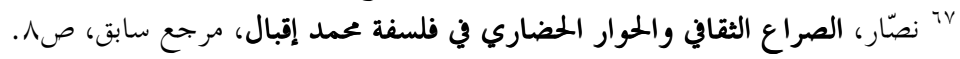

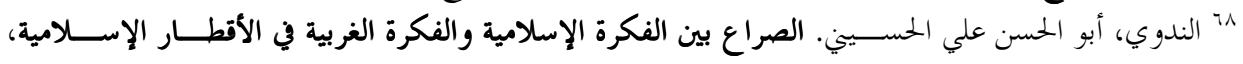

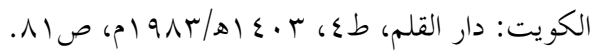


ولعل هذا بخده في معظم أعمال إقبال، سواء الثريـــة أو الشـــعرية، خاصـــة أن الحضارة الغربية - كما يرى إقبال - استلمت مشعل الحضارة و الفكر بعد أن توقــف عطاء الحضارة الإسالامية في القرون الأخيرة. وللحاجة إلى بتحيد التفكير الإسلامي، رأى إقبال أن "واجبنا يقتضي أن نرقب في يقضة وعناية تقدّم الفكر الإنساني، وأن نقف منه موقف النقد و التمحيص.."19 خاصة

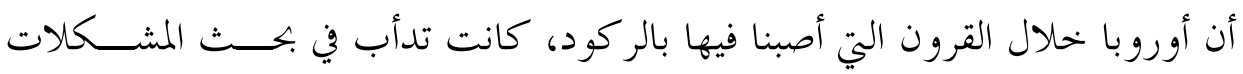
الكبرى، و حدث تقدم لا حدّ له في بحال الفكر و التجربة، و كان من نتـــائج امتــــداد سلطان الإنسان على الطبيعة، أن بعث فيه ذلك إيماناً و إحساساً جديدين بتفوقه علــى ولى ولى القوى التي تتألف منها بيئته، فظهرت و جهات نظر جديدة، و وحــــررت مـــرة ثانيـــة المشكالات القديمة في ضوء التجربة الحلديثة، وظهرت مشكالات من نوع جلديد. فتطور التفكير العلمي اكتسب تطورات جديدة وفتح للإنسان آفاقاً جديدة مــن النظر إلى المشكلات الجلديدة، و لهذا لا عجب أن بخد الشباب المســلم.... يتطلبـــون تو جيهاً جديداً بعقيدةم، و ولذا فإن صحوة المسلمين ويقضتهم تحتاج أن يصاحبها نقد و تمحيص برو ح مستقالً و مقارنة .بما عند الآخرين.

ولذلك فإن اليقظة الإسلامية تحتاج أن تححص و تنتقد نتائج هذه الحضارة المهيمنة، أو بتعبير إقبال "لا بدّ أن يصاحب يقظة المسلمين تمحيص بروح مستقلة لنتائج الفكـــر

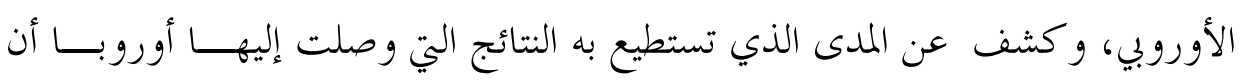

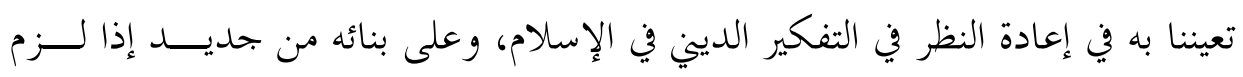

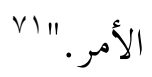

هذا التمحيص اقتضى توجيه نقده لمادية اللمضارة الغربية ولآثارها الخطيرة علـىى الشباب المسلم. 


\section{ب. نقد مادية الحضارة الغربية:}

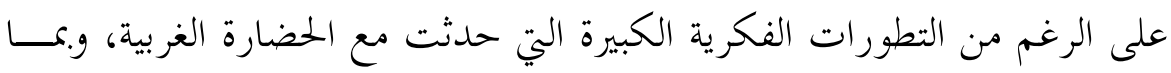

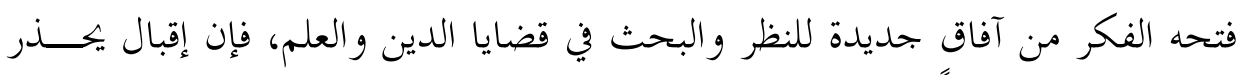
من الانبهار بالصورة الظاهرية، ونسيان عمق هذه الحضارة غير الديني.

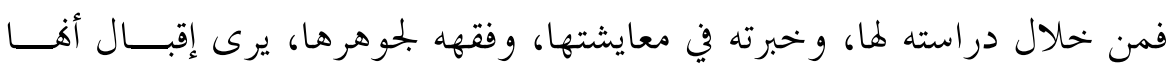

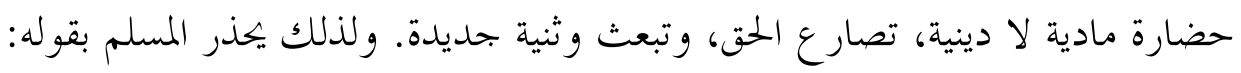

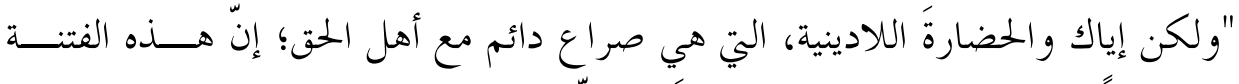

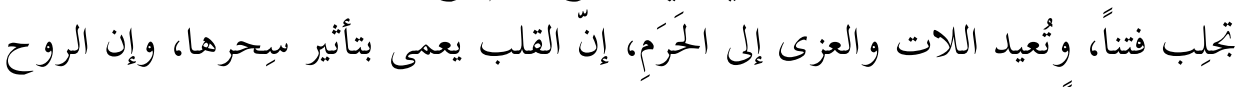

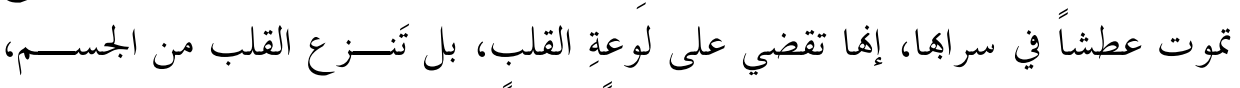

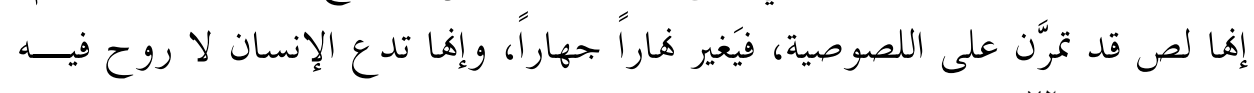
ولا قيمة له. Vr"

بل إن الحضارة الغربية الحلديثة لا تنفك تفتك بالإنسان و إنسانيته، وهي حضـــارة

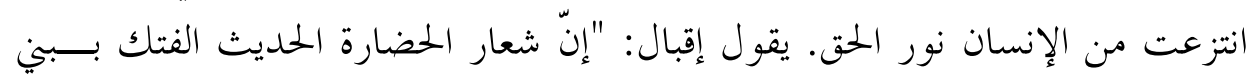

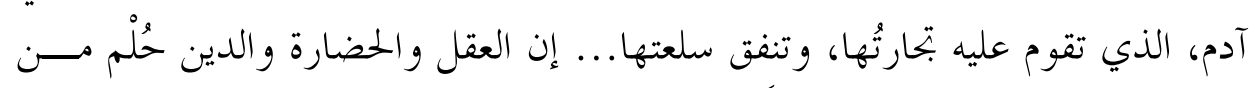

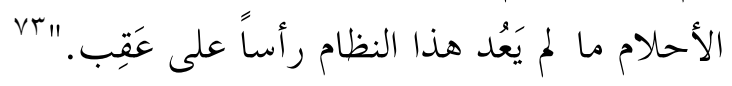

وهو يرى أن هذا البريق الذي تتمتع به الحضارة الغربية لا يؤثر فيه، يقول: "يـــــا

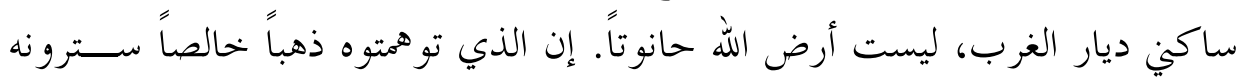

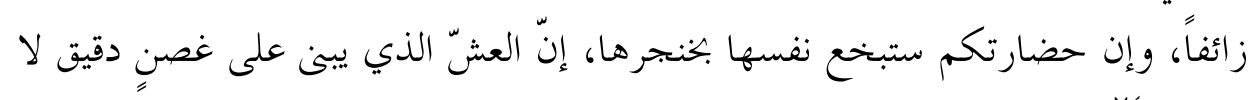
يثبت.

وهي حضارة خلت من العفة والروح وجمال الذوق والوجدان، لهذا فإنا ثقافتها

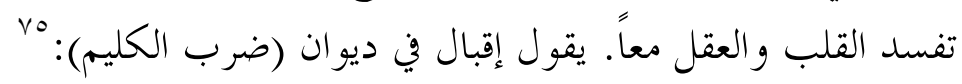

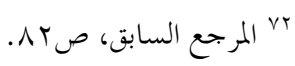

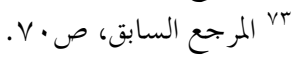

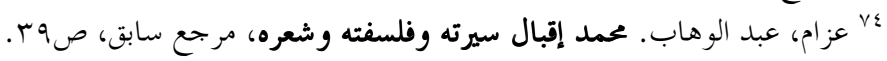

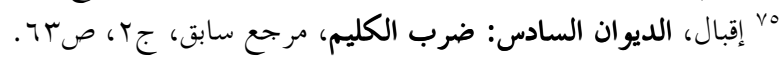




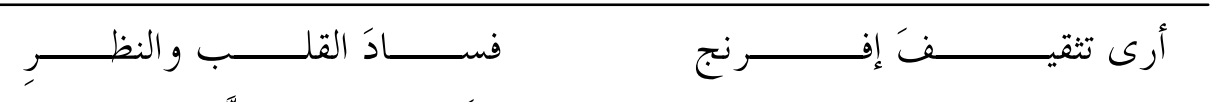

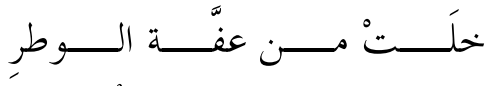

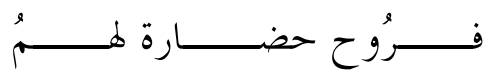

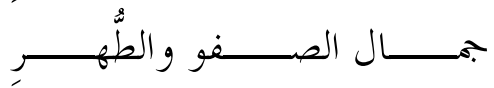

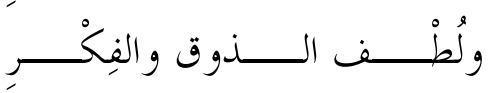

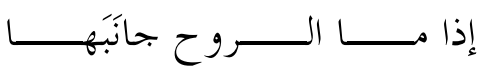

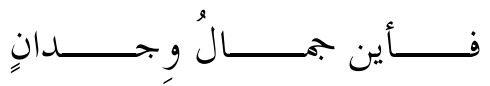

\section{ت. تقد التجديل بروح تغريبية:}

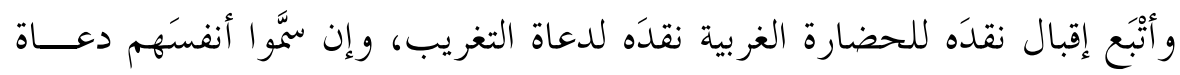
التجديد؛ الذين يُنادو ن بتقليد الحضارة الغربية بخيرها و شرها، و حُلوها ومرها.

وأبدى إقبال يأسه من زعماء التجديد في الشرق، فقد حضروا في نادي الشــرق بأكو اب فارغة و بضاعة مزجاة في العلم و الفكر، ورأى أهم يعبثون .محاولتهم التجديد هذه الروح التغريبية التي لم تحافظ على القليع ولا هي جاءت بجديد نافع؛ إذ يقول: يئست فــال أرجّهـي في أنـــاس

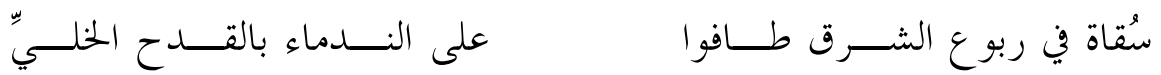

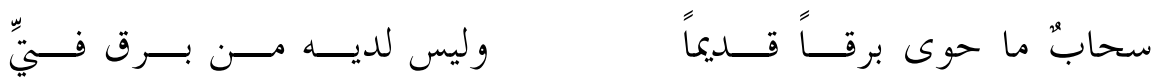

ويسيء إقبال الظنّ بدعاة التجديد، ويكشف سترهم بأن هذا التجديد ما هو إلا حيلة لتقليد الغرب، ويكمل بشدة على التغريب، ويعيب على من تبنى التغريب "الطابع العلماني الذي انتحلوه عن الغرب في السياسة و التعليم و الاجتماع، و وأكدّ أفم ضــلّوا سبيل الرشاد في فصلهم الدين عن الدولة، وإغلاقهم المعاهد الدينية، وإعلائهم العصبية القومية على الهوية الإسالامية، ودعوقم لسفور المرأة ومساواتا بالرجل في الميراث.. و يدعو المسلم إلى الاعتزاز بشخصيَّه و كِيانه، ويرى أن الذي يأتي بالجلديد في هذا

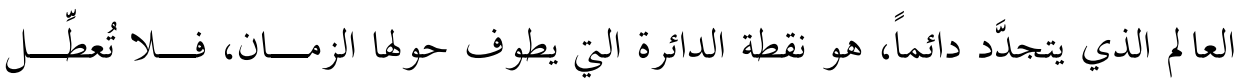

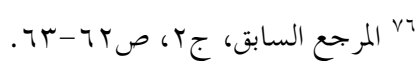

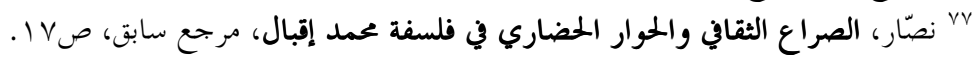




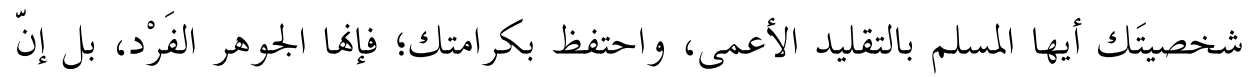

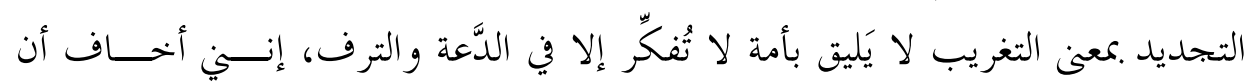

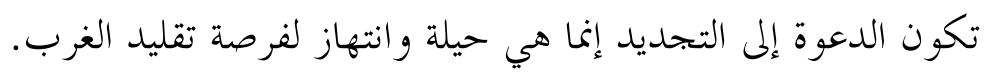

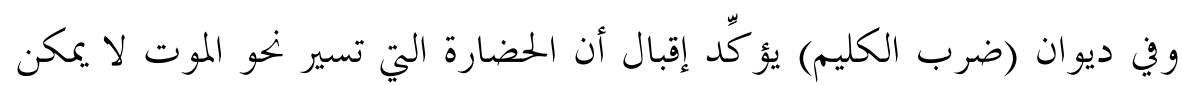

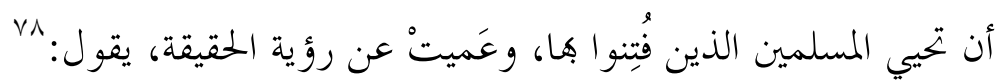

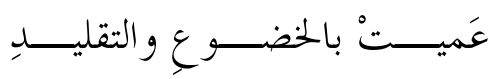

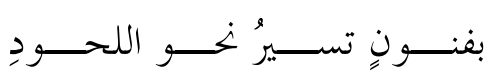

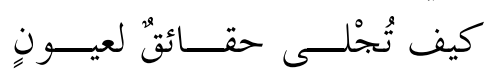
كيف يُحيي الفرنجُ عربًا وفُرسًا

خحتمة:

إنّ الفكر الحضاري الإسلامي في سعيه إلى إبحاز تنظيري للأطروحة الحضارية التي

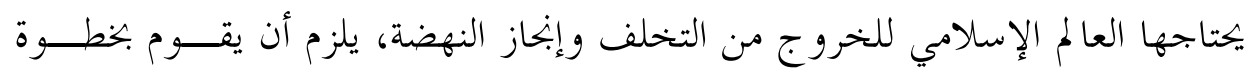

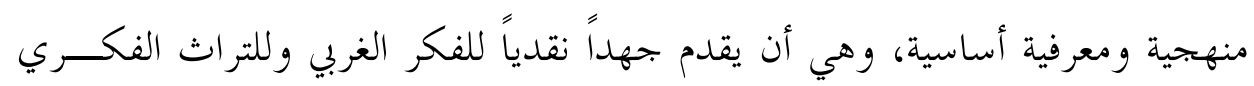

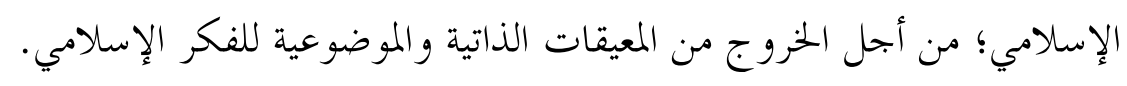
وفي هذا السياق يؤ كد محمد إقبال أن صحوتنا الحضارية تنطلق مــن تقـــيم ذاتي

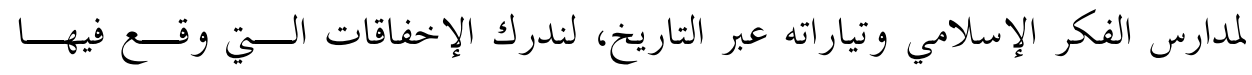

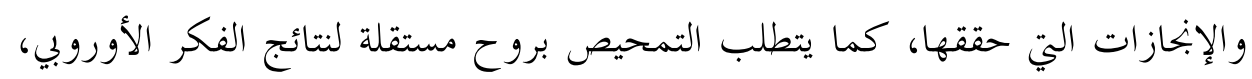

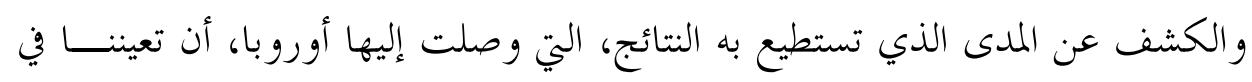
إعادة النظر في فكرنا الإسلامي وعلى بنائه من جديد إذي إذا لزم الأمر. لذلك فإن محمد إقبال في كتابه (بحديد التفكير الديني في الإسلام) وفي بقية أعماله

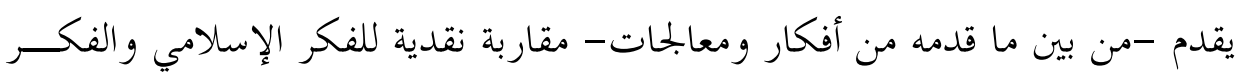
الغربي، مما يعدّ تأسيساً لأهمية المدخل النقدي في عملية بتحديد الفكر الإسلامي. 


\section{خحاتمة شعرية:}

في الأسطر الأخيرة في هاية كتاب (بحديد التفكير الديني) بند أنه ختمه بقصــيدة

شعرية أر اد منها مسك الختام، وجاء في مطلع القصيدة:

أنشد العون من شهود ثلاثة لتتحرى حقيقة مقامك

أو هلا عرفانك لذاتك

فانظر نفسك في نورك أنت

و الثاني معرفة ذات أخرى

فانظر نفسك في نور ذات سواك

و الثالث المعرفة الإلهية

فانظر نفسك في نور الله

فإذا كنت ثابت الروع في حضرة نوره فاعتبر نفسك حياً باقياً مثله. 